\title{
Impacts of future climate change and effects of biogenic emissions on surface ozone and particulate matter concentrations in the United States
}

\author{
Y. F. Lam $^{1}$, J. S. Fu ${ }^{1}$, S. Wu ${ }^{2}$, and L. J. Mickley ${ }^{3}$ \\ ${ }^{1}$ Department of Civil and Environmental Engineering, University of Tennessee at Knoxville, Knoxville, Tennessee, USA \\ ${ }^{2}$ Department of Geological and Mining Engineering and Sciences \& Department of Civil and Environmental Engineering, \\ Michigan Technological University, Houghton, Michigan, USA \\ ${ }^{3}$ School of Engineering and Applied Sciences, Harvard University, Cambridge, Massachusetts, USA
}

Received: 15 November 2010 - Published in Atmos. Chem. Phys. Discuss.: 21 January 2011

Revised: 28 April 2011 - Accepted: 1 May 2011 - Published: 23 May 2011

\begin{abstract}
Simulations of present and future average regional ozone and $\mathrm{PM}_{2.5}$ concentrations over the United States were performed to investigate the potential impacts of global climate change and emissions on regional air quality using CMAQ. Various emissions and climate conditions with different biogenic emissions and domain resolutions were implemented to study the sensitivity of future air quality trends from the impacts of changing biogenic emissions. A comparison of GEOS-Chem and CMAQ was performed to investigate the effect of downscaling on the prediction of future air quality trends. For ozone, the impacts of global climate change are relatively smaller when compared to the impacts of anticipated future emissions reduction, except for the Northeast area, where increasing biogenic emissions due to climate change have stronger positive effects (increases) to the regional ozone air quality. The combination effect from both climate change and emission reductions leads to approximately a $10 \%$ or $5 \mathrm{ppbv}$ decrease of the maximum daily average eight-hour ozone (MDA8) over the Eastern United States. For $\mathrm{PM}_{2.5}$, the impacts of global climate change have shown insignificant effect, where as the impacts of anticipated future emissions reduction account for the majority of overall $\mathrm{PM}_{2.5}$ reductions. The annual average 24-h $\mathrm{PM}_{2.5}$ of the future-year condition was found to be about $40 \%$ lower than the one from the present-year condition, of which $60 \%$ of its overall reductions are contributed to by the decrease of $\mathrm{SO}_{4}$ and $\mathrm{NO}_{3}$ particulate matters. Changing the biogenic emissions model increases the MDA8 ozone by
\end{abstract}

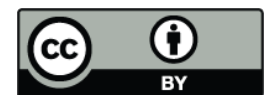

Correspondence to: J. S. Fu

(jsfu@utk.edu) about $5-10 \%$ or $3-5$ ppbv in the Northeast area. Conversely, it reduces the annual average $\mathrm{PM}_{2.5}$ by $5 \%$ or $1.0 \mu \mathrm{g} \mathrm{m}^{-3}$ in the Southeast region.

\section{Introduction}

Properly representing the transport and chemical transformation of air pollutants has always been one of the greatest challenges of simulating regional air quality in global climate/chemistry models. The accuracy of the results strongly depends on the selection of grid resolution (i.e., usually $\approx 1^{\circ} \times 1^{\circ}$ or large), land use information, emissions input and temporal resolution (i.e., 3-h) (Chin et al., 2007; Civerolo et al., 2007; Ito et al., 2009; Knutti et al., 2008; Wu et al., 2007; Fiore et al., 2005; Avise et al., 2009). It has been observed that the coarse resolution used by global models may not be sufficient to represent appropriate meteorological characteristics of some regions (i.e., complex terrain regions) because of over-simplifying the vertical grid structure and land use information in the models (Arunachalam et al., 2006; Kim et al., 2010). Nevertheless, global models have been widely recognized as a practical tool for predicting long-term climate and air quality trends, evaluating intercontinental longrange transport of air pollutants and large-scale climate and air quality impact studies, such as those on dust storms and the stratospheric ozone hole (Wu et al., 2008b; Chin et al., 2007; Vingarzan, 2004). To integrate useful information from global models into regional-scale models, methodologies of downscaling global climate and chemistry outputs have been developed in recent years for resolving the issue of insufficient temporal and spatial resolutions (Lam and $\mathrm{Fu}$,

Published by Copernicus Publications on behalf of the European Geosciences Union. 
2010). The term "downscale/downscaling" refers to the technique for enquiring global climate/chemistry model output as the input for regional climate/air quality model to study regional/local phenomena. Various air quality studies have implemented the downscaling methodologies for evaluating the influence of climate change, land-use modification, and different emissions projection scenarios on both anthropogenic and biogenic emissions on the regional scale in the United States (Civerolo et al., 2007; Jiang et al., 2008; Jacobson and Streets, 2009; Zhang et al., 2008).

A wide range of temperature and ozone concentration changes have been reported from both global and regional model studies in the United States. Depending on the type of model used and emissions projection scenarios (i.e., the IPCC A1B) selected, the projected future ozone concentrations vary greatly. In global model, Wu et al. (2008b) have projected a $1-3{ }^{\circ} \mathrm{C}$ temperature increase for 2050 , which would result in an extra $2-5 \mathrm{ppbv}$ of surface ozone in the Northeast and the Mid-north of the United States and a reduction of ozone in the Southeast United States on a nonemission change scenario using GISS-GCM/GEOS-Chem coupling models. They also found that the anticipated emissions reductions $\left(40 \%\right.$ for $\left.\mathrm{NO}_{\mathrm{X}}\right)$ in the IPCC A1B scenario would have a greater effect (i.e., -2 to -15 ppbv) than the climate change (i.e., +2 to +5 ppbv) on the maximum daily 8-h ozone. Huang et al. (2008) simulated the future air quality in 2048-2052 (summer) using the Model for Ozone And Related chemical Tracers (MOZART) under the IPCC A1Fi (i.e., fossil intensive) and the B1 (i.e., clean technology intensive) scenarios. They found that the Southeast United States would have the largest sensitivity of surface ozone in response to the emission changes with $+25 \%$ to $-24 \%$ for the A1Fi and B1 scenarios in 2048-2052, while less sensitivity of surface ozone would be shown on the Midwest and the Northeast of the United States and Texas. They suggested that the future US air quality projected by MOZART is less sensitive to the emissions scenarios simulated by SARMAP air quality model in those locations (Huang and Chang, 2001). It is doubtful that they have found that the trend of surface ozone mixing ratio from MOZART is consistently higher than SARMAP, which is unlikely to occur at a coarse grid resolution. They commented that the overestimation of ozone in MOZART was caused by over-estimation of anthropogenic emissions. Their study revives the important notion that consistent emission input for the global and the regional models should be used when model comparisons are performed.

In regional model, the downscaled results on the impacts of climate change have also varied largely across the geospatial regions. Some studies have found that climate change has large adverse effects on future air quality. The large increase of temperature (i.e., $1-2 \mathrm{~K}$ ) has encouraged the formation of ozone and resulted in an extra 5-10 ppbv compared to the present air quality condition. Bell et al. (2007), Nolte et al. (2008) and Dawson et al. (2008) found that the sensi- tivity of temperature change in the regional ozone averages $0.34 \mathrm{ppbv} \mathrm{K}^{-1}$ (i.e., $1-3 \mathrm{ppbv}$ for a $2.5 \mathrm{~K}$ increase) for the Eastern United States. They also suggested that a $2.5 \mathrm{~K}$ increase of temperature leads to a $30 \%$ increase of exceedance on the maximum daily average 8-h ozone (MDA8) standard. Bell et al. (2007) found that the climate change alone contributed an increase of $4.8 \mathrm{ppbv}$ on average ozone across the United States, with the largest increase at $9.6 \mathrm{ppbv}$, which corresponds to an additional $68 \%$ of exceedances in the 8-h standard in 2050. Although the effect of climate change on temperature and stagnant air flow would encourage the formation of ozone, most researchers have found that the anticipated emissions reduction from IPCC cases (i.e. A1B) in the United States tends to compensate for the effect of climate change on ozone formation with or without considering the change of Biogenic Volatile Organic Compounds (BVOC) in future. The overall ozone reduction is projected to be -4 to $-15 \%$ in 2050. It is suggested that effects of anthropogenic emissions account for more overall change of ozone formation than the climate change (Tagaris et al., 2007; Jacob and Winner, 2009; Nolte et al., 2008; Zhang et al., 2008).

The accuracy of these studies has been tied strongly to the methodology used for downscaling, the choice of resolution, and selection of projection emission scenarios. It is observed that most of the climate studies mentioned above have used the Biogenic Emissions Inventory System (BEIS3) v3.x for estimating BVOC emissions (Weaver et al., 2009). While recent studies showing that BEIS3 may have underestimated isoprene emission compared to the Model of Emissions of Gases and Aerosols from Nature (MEGAN2) v2.0x, these studies may also lead to underestimating the effect of climate change in the VOC-limited region, such as in the Northeast region of the United States (Sakulyanontvittaya et al., 2008; Guenther et al., 2006; Fiore et al., 2005; Kunkel et al., 2008). The estimates of biogenic isoprene emission from MEGAN2 are about $50 \%$ more than the estimates from BEIS3 (Pouliot, 2008; Pouliot and Pierce, 2009). It is possible that the additional BVOC from MEGAN2 may lead to a large increase of ozone. Moreover, it alters the relationship found between the effect of climate change and the effect of change of anthropogenic emissions in previous studies. Furthermore, the majority of these climate change studies have used grid resolutions of $30 \mathrm{~km}$ or larger (except for Hogrefe et al., 2007), with recent studies suggesting that $12 \mathrm{~km}$ resolution may be the better choice for studying regional air quality, and that the grid resolutions of $30 \mathrm{~km}$ or larger may produce an additional bias to climate change studies and may result in underestimation of ozone formation in regional-scale studies (Hogrefe et al., 2007a, b; Kim et al., 2010). Since the sensitivities of scalability and the effects of BVOC on the climate change scenarios have not been studied, revisiting the future air quality with the implementation of those concepts is important to further investigate the effect of climate change on a regional scale. 
In this study, three years of air quality with present/future climate conditions were simulated using the Community Multi-scale Air Quality Modeling System (CMAQ) to examine the effect of climate change on regional air quality under IPCC A1B emissions scenarios. We downscaled GISS General Circulation Model (GISS GCM III) and GEOS-Chem model outputs according to the framework of Global Change and Air Pollution (GCAP) to obtain a proper present-future climate and chemical boundary conditions for the simulations (Jacob et al., 2009). In the manuscript, unless specified otherwise, the present/future climate in here refers to 1999-2001 for the present climate and 2049-2051 for the future climate. Due to the concern of the effects of biogenic emission in the regional climate study, air quality simulations of present/future climate conditions (2000 and 2050) with MEGAN2 biogenic emissions scenario at $12 \mathrm{~km}$ resolution were performed to investigate the effect of changing of biogenic emissions in the Southeastern United States.

Overall, we concentrated on three aspects of climate change/air quality studies: (1) The regional impacts on air quality from global climate change (i.e., Southeastern United States). Since very limited studies have documented fine resolution results in climate change/air quality studies, these results provide additional insight into the effect of model resolution selection to the future climate and air quality predictions; (2) the comparison of global model results (i.e., $4^{\circ} \times 5^{\circ}$ resolution) with regional outputs results (i.e., $36 \mathrm{~km}$ and $12 \mathrm{~km}$ resolution) to identify the discrepancy in the prediction of future regional air quality trends between the global model and the regional model; and (3) the impacts of using different biogenic emissions inventories (i.e., BIES3 and MEGAN2 on fine resolution CMAQ) on the future air quality studies and the role of BVOC in the future climate studies. In the study, ozone $\left(\mathrm{O}_{3}\right)$ and fine particulates $\left(\mathrm{PM}_{2.5}\right)$ were the focus since they have significant impacts on human health. Eight scenarios were performed, which include various combinations of emissions scenarios within present and future meteorology. We do not include the impacts of future land cover changes, which is highly uncertain in the future climate. It is expected that this study will provide a broader understanding of the discrepancy between global and regional outputs for air quality application in the area of future climate change scenarios.

\section{Methodology - GCAP modeling system}

The GCAP modeling system consists of four models, spanning from global to regional scales. In global model, the GEOS-Chem modeling system driven by the GISS III GCM was used to provide global air quality conditions in a coarse resolution. Details of the global chemical and meteorological models implemented in the present study can be found in Schmidt et al. (2006) and Wu et al. (2008a). In regional model, the outputs of the GEOS-Chem were downscaled to provide chemical initial and boundary conditions for CMAQ, while the outputs of the GISS GCM III were used as the inputs for the Penn State/NCAR Mesoscale Model (MM5). Descriptions of the models' setup and emission scenarios are discussed below.

\subsection{Global models}

The GEOS-Chem Chemical Transport Model (CTM) driven by meteorological fields from the GISS GCM III (an updated version of the model described by Rind et al., 1999) was used to simulate the present and future air quality in the United States. The GISS GCM III simulation was initialized on 1 June 1950 and continuously simulated to the end of 2050. The resolution of $4^{\circ} \times 5^{\circ}$ with 23 vertical layers extending from the surface to $0.002 \mathrm{hPa}$ (up to $85 \mathrm{~km}$ in altitude) was used to simulate the transient climate (Rind et al., 2007). For meteorological consistency, the same temporal resolution was used in the GEOS-Chem CTM with 3-h meteorological data of mixing depths and surface variables (i.e., surface temperature; surface winds; precipitation and albedo; and solar radiation) and 6-h meteorological data (i.e., winds, convective mass fluxes, temperature, humidity, cloud optical depths, and cloud fractions) generated from the GISS GCM III. In this study, GEOS-Chem (v7.03.06) was used, which includes a coupled treatment on tropospheric ozone-NOx-VOC chemistry and aerosols, to simulate both ozone and $\mathrm{PM}_{2.5}$ concentrations in the US (Park et al., 2004). Four scenarios were evaluated: (1) present meteorology with present emissions, (2) present meteorology with future emissions, (3) future meteorology with present emissions, and (4) future meteorology with future emissions. The descriptions of the forecasted future emissions are described in the emissions section. Three years of simulations were conducted for each climate scenario (i.e., three years of present climate and three years of future climate), which were initialized on 1 September and continued for 40 months. The first four months served for proper initialization, and the following 36 months were used as the actual simulation results. Details of the global models' set-up are described by Wu et al. (2007).

\subsection{Regional models}

The initial and boundary conditions of the regional models (both MM5 and CMAQ) were downscaled from the outputs of the global models' simulations (GISS GCM III and GEOS-Chem). For GISS downscaling, the GISS GCM III outputs were interpreted and interpolated into the format accepted by the MM5 preprocessor, REGRID, to provide meteorological initial and boundary conditions for MM5. For GEOS-Chem downscaling, the GEOSChem outputs were undergone time-step interpolation, vertical and horizontal interpolations, chemical species conversion, appending chemical species, and unit conversion to achieve CMAQ model-ready initial and boundary conditions. 
Table 1. MM5 and CMAQ model configurations for present and future simulations.

\begin{tabular}{ll}
\hline \multicolumn{2}{c}{ MM5 Configuration } \\
Model version & 3.7 \\
\hline Number of sigma level & 34 \\
Number of grid & $169 \times 133 / 181 \times 190$ \\
Horizontal resolution & $36 \mathrm{~km} / 12 \mathrm{~km}$ \\
Map projection & Lambert conformal \\
FDDA & Analysis nudging \\
Cumulus & Kain-Fritsch 2 \\
Microphysics & Mix-phase \\
Radiation & RRTM \\
PBL & Mellor-Yamada-Janjic (Eta) \\
LSM & Noah LSM \\
LULC & USGS 25-Category \\
\hline & CMAQ Configuration \\
\hline Model version & 4.6 \\
Number of layer & 14 \\
Number of grid & $148 \times 112 / 177 \times 168$ \\
Horizontal resolution & $36 \mathrm{~km} / 12 \mathrm{~km}$ \\
Horizontal advection & PPM \\
Vertical advection & PPM \\
Aerosol module & AERO4 \\
Aqueous module & CB-IV \\
Emission & EPA's NEI 1999 \\
Boundary condition & GEOS-Chem* \\
\hline
\end{tabular}

* Corresponding year of GEOS-Chem outputs are used.

Details of the downscaling methodology are described in Lam and Fu (2010).

The CMAQ was driven by NCAR's fifth-generation Mesoscale Model v3.7 (MM5), with hourly resolution. The horizontal resolutions of $36 \mathrm{~km}$ and $12 \mathrm{~km}$ with 34 sigma vertical layers were used. All MM5 simulations were conducted using the one-way nested approach from $108 \mathrm{~km}$ over North America $\left(140-40^{\circ} \mathrm{W}, 10-60^{\circ} \mathrm{N}\right)$ down to $36 \mathrm{~km}$ continental US $\left(128-55^{\circ} \mathrm{W}, 21-50^{\circ} \mathrm{N}\right)$ and eventually down to $12 \mathrm{~km}$ VISTAS domain $\left(96-71^{\circ} \mathrm{W}, 23-45^{\circ} \mathrm{N}\right)$, as shown in Fig. 1. For meteorological initial and boundary conditions, the GISS GCM III data with resolution of $4^{\circ} \times 5^{\circ}$ was used with the 4-D analysis nudging technique to reproduce the weather conditions similar to the GISS GCM III outputs. The Kain-Fritsch cumulus, Mix-phase micro-physic, RRTM long-wave radiations, Eta planetary boundary layer (PBL) and NOAH land surface model (LSM) were configured in the simulations. A detailed summary of the MM5 configuration is shown in Table 1. For CMAQ, the Lambert conformal projection with true latitude limits of 25 and 40 was used on 148 by 112 grid cells and on 177 by 168 grid cells with horizontal resolution of $36 \mathrm{~km}$ and $12 \mathrm{~km}$, respectively. The center of the horizontal domain was set at $100^{\circ} \mathrm{W}$ and $40^{\circ} \mathrm{N}$. The $36 \mathrm{~km}$ domain covers the entire continental US and part

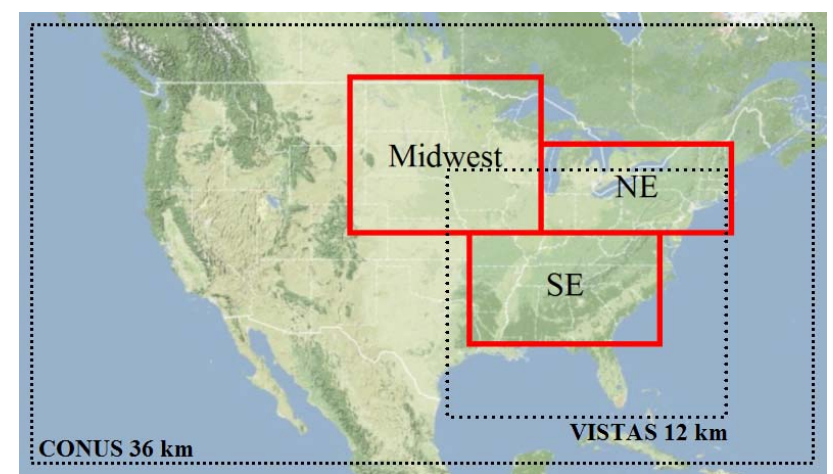

Fig. 1. The CONUS $36 \mathrm{~km}$ and VISTAS $12 \mathrm{~km}$ domains with selected study areas boxed in red (the dark green color on the map indicates locations of vegetation).

of Mexico and Canada (referred to as CONUS domain) and the $12 \mathrm{~km}$ domain covers all the southeastern states. A total of 14 sigma vertical layers were extracted from MM5 with the lowest model levels centered at approximately 18, 52, $105,215,360$ and $545 \mathrm{~m}$ above the surface. For CMAQ simulations, the same scenarios described in the GEOS-Chem, with additional simulations on biogenic emissions (BEIS3 and MEGAN2 emissions scenarios), were performed to investigate the sensitivities of climate change from biogenic emissions on a regional scale. All of these simulations were configured with the Carbon Bond IV (CB-IV) chemical mechanism with aerosol module (AERO4) with boundary conditions generated from downscaling GEOS-Chem outputs. Please noted that the AERO4 does not include aerosol pathway from isoprene to secondary organic aerosol (SOA), which may lead to underestimation of $\mathrm{PM}_{2.5}$ in CMAQ. The detailed configuration of CMAQ setting is also listed in the Table 1.

\subsection{Emissions and simulation scenarios}

\subsubsection{Anthropogenic emissions}

The base year for the present-day anthropogenic emission inventories is 2000. These emission files are based on the 1999 EPA's National Emissions Inventories (NEI 1999), 1995 Canadian point sources for Eastern Canada and 2000 Environment Canada (EC) area and mobile inventories (http: //www.ec.gc.ca/inrp-npri), and the 1999 BRAVO Mexican emission inventory. The emissions through the Sparse Matrix Operator Kernel Emission system (SMOKE 1.4) were processed to generate CMAQ-ready emission files for both 36 and $12 \mathrm{~km}$ domains. For the estimates of the futureyear anthropogenic emissions, we first calculated the future monthly projection rates/growth factors based on the IPCC A1B scenario for ozone and aerosol precursors emissions using the integrated Model to Assess the Greenhouse Effect (IMAGE socioeconomic model) and IMAGE managed forest 
Table 2. The annual projection rates of anthropogenic emissions from present to future.

\begin{tabular}{|c|c|c|c|c|c|c|c|}
\hline \multirow[t]{2}{*}{ CMAQ species** } & \multicolumn{3}{|c|}{ By category* } & \multicolumn{4}{|c|}{ By region } \\
\hline & Fossil fuels & Biofuel & Biomass burning & CONUS & Northeast & Southeast & Midwest \\
\hline $\mathrm{NO}_{2}$ & -- & - & + & 0.64 & 0.55 & 0.54 & 0.54 \\
\hline $\mathrm{CO}$ & - & - & + & 0.83 & 0.64 & 0.69 & 0.69 \\
\hline ALD2 & - & - & ++ & 1.40 & 1.91 & 2.24 & 1.83 \\
\hline FORM & - & - & ++ & 1.41 & 1.91 & 2.24 & 1.84 \\
\hline OLE2 & - & - & + & 0.74 & 0.52 & 0.50 & 0.53 \\
\hline PAR & - & - & + & 0.77 & 0.56 & 0.53 & 0.54 \\
\hline NH3 & - & - & $=$ & 1.21 & 1.25 & 1.27 & 1.35 \\
\hline PMC & - & - & $=$ & 0.62 & 0.50 & 0.62 & 0.63 \\
\hline $\mathrm{PM}_{10}$ & - & - & $=$ & 0.62 & 0.50 & 0.62 & 0.63 \\
\hline PMFINE & - & - & $=$ & 0.62 & 0.50 & 0.62 & 0.83 \\
\hline PEC & - & - & $=$ & 0.73 & 0.59 & 0.57 & 0.48 \\
\hline POA & - & - & $=$ & 0.63 & 0.54 & 0.65 & 0.67 \\
\hline PSO4 & -- & - & ++ & 0.61 & 0.44 & 0.36 & 0.24 \\
\hline $\mathrm{SO}_{2}$ & -- & - & ++ & 0.68 & 0.46 & 0.37 & 0.28 \\
\hline
\end{tabular}

* "=" is the value within $\pm 10 \%$, "-_" is $10-50 \%$ of reduction, "- - " is more than $50 \%$ of reduction, "+" is $10-50 \%$ of increase and "++" is more than $50 \%$ of increase.

** $\mathrm{NO}_{2}$ - nitrogen dioxide; CO - carbon monoxide; ALD2 - higher aldehyde; FORM - formaldehyde; OLE2 - olefin; PAR - paraffin; NH3 - ammonia; PMC - particles in the 2.5-10 $\mu \mathrm{m}$ diameter; $\mathrm{PM}_{10}$ - particles with less than $10 \mu \mathrm{m}$ in diameter; PMFINE - other primary $\mathrm{PM}_{2.5}$; PEC - primary elemental carbon; POA - primary organic aerosol; PSO4 - primary sulfate; and $\mathrm{SO}_{2}-$ sulfur dioxide.

projections (Streets et al., 2004). Afterward, we applied these monthly growth factors to different emission categories of present-day emissions files to generate future-year emissions for each day. It should be noted that the same methodology described above has been applied for simulations with both GEOS-Chem and CMAQ to maintain emissions consistency between the global and the regional models. The overall $\mathrm{NO}_{\mathrm{x}}$ and VOC differences between those two models were estimated to be less than $10 \%$. The calculated total $\mathrm{NO}_{\mathrm{x}}$ and VOC emissions in the US were 19.4 and $15.7 \mathrm{Tg}$ year $^{-1}$ for the GEOS-Chem and were 21.0 and 17.2 $\mathrm{Tg}_{\text {year }}{ }^{-1}$ for the CMAQ, respectively. Table 2 lists the summary of annual anthropogenic emission growth rates used in this study. To simplify model comparisons, the same sub-domain definitions described in Wu et al. (2008b), were implemented, as shown in Fig. 1. The sub-domains include three areas: (1) Northeast, (2) Southeast, and (3) Midwest. The Northeast domain covers all the eastern states from Indiana to the Atlantic coast in an east-west direction, and from Kentucky to Michigan in a south-north direction $\left(87.5-67.7^{\circ} \mathrm{W}\right.$, $37.2-45.7^{\circ} \mathrm{N}$ ); The Southeast domain includes the majority of the Visibility Improvement State and Tribal Association of the Southeast (VISTAS) states, with half of Kentucky and West Virginia $\left(97.6-73.3^{\circ} \mathrm{W}, 29.8-37.2^{\circ} \mathrm{N}\right)$; The Midwest domain contains all the mid-northern states, up to the middle of Wyoming. (107.4-87.5 $\left.\mathrm{W}, 38.6-49.8^{\circ} \mathrm{N}\right)$.

As shown in Table 2, a large increase of acetaldehyde (ALD2) and formaldehyde (FORM) were projected as a result of the increase of the biomass burning in the future. The projection values could be up to 2.5 times higher than the present-day emissions. The growth of these emissions was mainly contributed by the IMAGE managed forest projections, where supplemented estimates of wildfire emissions from the mature forest were used. In contrast, a huge reduction of sulfur dioxide $\left(\mathrm{SO}_{2}\right)$ was proposed due to the anticipated future fuel emissions controls. For nitrogen oxide $\left(\mathrm{NO}_{2}\right)$, an overall reduction of $60 \%$ was forecast across the Eastern US, with the largest reductions of 60 to $70 \%$ in the fossil fuel combustion sector. It should be noted that these $\mathrm{NO}_{2}$ reductions in the US, have been compensated for by the increased emissions in Mexico and yield a smaller reduction factor (0.64) for the continental US domain.

\subsubsection{Biogenic emissions}

For biogenic emissions, two emission factor-based models, the Biogenic Emissions Inventory System (BEIS3) v3.12 and the Model of Emissions of Gases and Aerosols from Nature (MEGAN2) v2.02 (http://bai.acd.ucar.edu/Megan/index. shtml), were used to generate the hourly biogenic emissions inventories for both present and future climate scenarios. Corresponding years of temperature and solar radiation data generated from the Meteorology-Chemistry Interface Processor (MCIP) were used to take into account the change of biogenic emissions from natural sources caused by the change in meteorological conditions. It should be noted that, in the study, two separate datasets were generated, which are: (1) BEIS3 dataset for 2000 and 2050, and (2) MEGAN2 dataset for both present/future conditions (1999-2001 and 2049-2051). A spatial resolution of $1 \mathrm{~km}$ land use and vegetation was employed in the 36 and $12 \mathrm{~km}$ domains on both biogenic models. We assumed the same 
Table 3. The breakdown of species concentrations of the present-year biogenic emissions from BEIS3 and MEGAN2, with comparisons of the present-year (2000) and future-year (2050) biogenic emissions.

\begin{tabular}{|c|c|c|c|c|c|c|c|c|c|c|c|}
\hline \multirow[t]{3}{*}{ Species* } & \multirow[t]{3}{*}{ Factor (mole) } & \multicolumn{8}{|c|}{ Present climate (2000) } & \multirow{2}{*}{\multicolumn{2}{|c|}{$\begin{array}{c}\text { \% Growth rate }(2050-2000) \\
\text { CONUS }\end{array}$}} \\
\hline & & \multicolumn{2}{|c|}{ CONUS } & \multicolumn{2}{|c|}{ Midwest } & \multicolumn{2}{|c|}{ Northeast } & \multicolumn{2}{|c|}{ Southeast } & & \\
\hline & & MEGAN2 & BEIS3 & MEGAN2 & BEIS3 & MEGAN2 & BEIS3 & MEGAN2 & BEIS3 & MEGAN2 & BEIS3 \\
\hline ALD2 & $\times 10^{9}$ & 162 & 149 & 17 & 13 & 11 & 6 & 36 & 28 & +24 & +19 \\
\hline ETH & $\times 10^{9}$ & 75 & 67 & 11 & 9 & 6 & 3 & 14 & 9 & +24 & +20 \\
\hline FORM & $\times 10^{9}$ & 16 & 59 & 2 & 8 & 1 & 3 & 3 & 8 & +24 & +20 \\
\hline ISOP & $\times 10^{9}$ & 294 & 192 & 26 & 21 & 30 & 14 & 76 & 47 & +40 & +23 \\
\hline NO & $\times 10^{9}$ & 71 & 112 & 7 & 8 & 5 & 4 & 17 & 21 & +21 & +19 \\
\hline OLE & $\times 10^{9}$ & 96 & 263 & 11 & 31 & 6 & 10 & 18 & 37 & +25 & +21 \\
\hline PAR & $\times 10^{9}$ & 1230 & 1515 & 160 & 167 & 92 & 57 & 245 & 228 & +23 & +21 \\
\hline TERPB & $\times 10^{9}$ & 71 & 112 & 7 & 8 & 5 & 4 & 17 & 21 & +21 & +19 \\
\hline TOL & $\times 10^{9}$ & 0.65 & 20.88 & 0.10 & 2.81 & 0.05 & 0.99 & 0.12 & 2.80 & +24 & +20 \\
\hline XYL & $\times 10^{9}$ & 0.92 & 0.62 & 0.07 & 0.10 & 0.07 & 0.07 & 0.21 & 0.16 & +21 & +18 \\
\hline VOC & $\times 10^{12}$ & 3397 & 3644 & 370 & 404 & 287 & 174 & 767 & 637 & +30 & +21 \\
\hline
\end{tabular}

* ALD2 - higher aldehyde (based on acetaldehyde); ETH - Ethene; FORM - formaldehyde; ISOP - isoprene; NO - nitric oxide; OLE - olefinic carbon bond; PAR - paraffin; TERPB - terprene; TOL - toluene, XYL - xylene; and VOC - total volatile organic compounds.
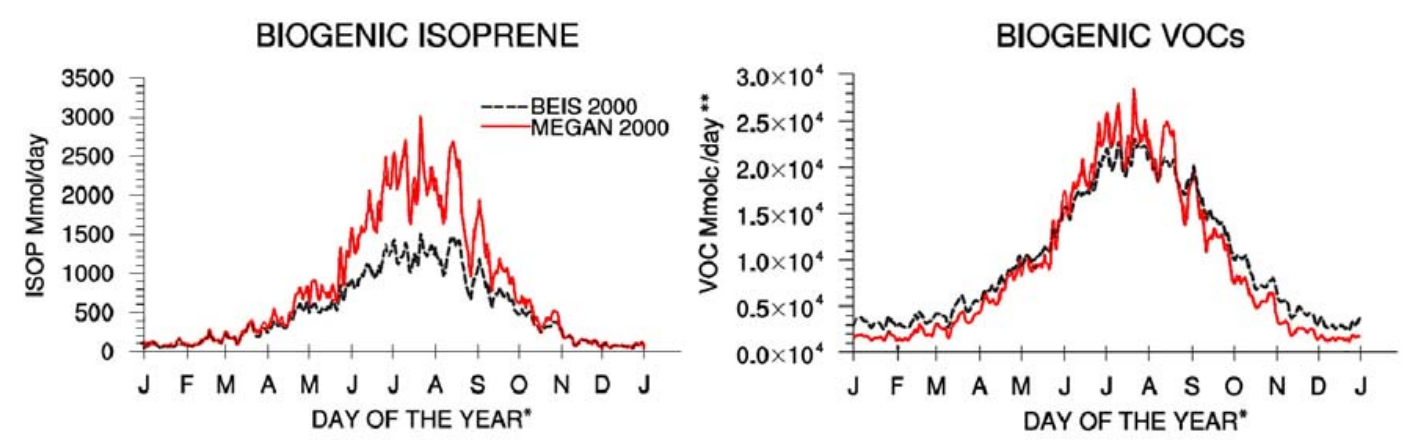

*J - January, F - February, M - March, A - APRIL, M - May, J - June, J - July, A - August, S - September, O - October, N - November, and D - December ** VOC Molc is calculated by PAR + 2OLE + $2 E T H+2 A L D 2+7 T O L+8 X Y L+5 I S O P+F O R M$

Fig. 2. CONUS $36 \mathrm{~km}$ daily domain totals of average biogenic emissions in 2000: (a) biogenic isoprene and (b) total biogenic VOC.

land use and vegetation patterns as 2000 on all years and all scenarios. These include the same leaf area index (LAI) and plant functional type (PFT) as well. The main differences between MEGAN2 and BEIS3 are the method of estimating isoprene emission and the emission factors used in the models (Sakulyanontvittaya et al., 2008). In BEIS3, the isoprene emission is calculated by empirical algorithms described in Guenther et al. (1993), which follows a mathematical function that depends on temperature and solar radiation. An increase in temperature causes an initial rise in isoprene emission trailed by a slow decline when the temperature reaches about $38^{\circ} \mathrm{C}$ (Zhang et al., 2008). In MEGAN2, isoprene is characterized by two separate emissions processes, the light-and-temperature-dependent direct emissions from chloroplasts without storage and purely temperaturedependent emissions from storage pools. Each process utilizes an individual dependence factor to adjust the total isoprene emission. MEGAN2 calculates the plant-specific isoprene emission by multiplying all those dependence factors with the base/standard emission factor for each type of plant.
Equation (1) shows the factor-based emission formula used in MEGAN2.

$\mathrm{EM}=\varepsilon \cdot \gamma_{\mathrm{LAI}} \cdot \gamma_{\mathrm{P}} \cdot \gamma_{T} \cdot \gamma_{\mathrm{CE}}$

where $\varepsilon$ is the base emission factor, $\gamma_{\mathrm{LAI}}$ is the Leaf Area Index Factor, $\gamma_{\mathrm{P}}$ is the PPFD Emission Activity Factor (lightdependence) and is a function of solar angle and above canopy Photosynthetic Photon Flux Density (PPFD), $\gamma_{T}$ is the Temperature Response Factor and $\gamma_{\text {age }}$ is the Leaf Age Factor. Sakulyanontvittaya (2008) estimated that the average hourly isoprene emissions in MEGAN2 are about $61 \%$ and $47 \%$ higher than the emissions generated by BEIS3 for July 2001 and January 2002, respectively. These emission differences are mainly resulted from the differences in the methodology, PTF, LAI and emissions factors used in the models. Arneth et al. (2007) suggested that the isoprene emission factor in BEIS3 was significantly lower than one in MEGAN2 which lead to the underestimation of total isoprene emission in BEIS3. In this study, the annual isoprene emission in MEGAN2 was about $53 \%$ higher than in 
BEIS3 in year 2000. Similar geospatial distributions of isoprene emissions were observed between the two models (not shown). Figure $2 \mathrm{a}$, b show the CONUS $36 \mathrm{~km}$ daily domain totals of isoprene and total BVOC emissions in BEIS3 and MEGA2. The major isoprene emission difference occurred in the months of May-September when heat and solar radiation are significantly high. For total BVOC, similar magnitudes of emissions (7\% difference in the CONUS domain) are found between the two models. However, significant geospatial disagreements were observed (not shown). For example, formaldehyde emissions in BEIS3 are distributed quite evenly throughout the United States, but the emissions in MEGAN2 are almost all centered in the Southeastern United States. These discrepancies of emission distributions potentially create differences in the predictions of air quality results between the two models.

Table 3 shows the emissions breakdown of the present year (2000) biogenic emissions from BEIS3 and MEGAN2. In the Northeast domain, MEGAN2 shows much larger emission values than BEIS3 on ALD2, ETH, ISOP, and PAR. The total biogenic VOC emissions in MEGAN2 is about $60 \%$ higher than in BEIS3. It is expected that the additional VOC emission in MEGAN2 may strongly affect the ozone production in the Northeast domain since the Northeast domain is considered as a VOC-limited area and is sensitive to an increase of BVOC. For the Midwest and Southeast domains, $-8 \%$ and $+20 \%$ of total VOC differences (MEGAN2 - BEIS3) were found, respectively. To investigate the effect of climate change, the differences in VOC emissions between 2050 and 2000 were also calculated, which is shown in the right side of the Table 3. As resulting from surface warming (i.e., $1.0-2.5^{\circ} \mathrm{C}$ ) and enhancement of solar radiation, both MEGAN2 and BEIS3 showed an increase of total biogenic emission by $30 \%$ and $21 \%$, respectively. These results $(+40 \%$ increase in isoprene in MEGAN2 and $+23 \%$ in BEIS3) were comparable to the values reported in the literature, where VOC emissions in BEIS3 and MEGAN2 are increased by $10-90 \%$ in the future year (Zhang et al., 2008; Hogrefe et al., 2004; Jiang et al., 2010). It is observed that the emissions estimated by MEGAN2 were much more climate sensitive than by BEIS3, with additional 3-5\% increase for most of VOC species and $10 \%$ increase for total biogenic VOC. The increase of VOC emission strengthens the impact of climate change on ozone air quality in the United States.

\subsubsection{Emissions scenarios}

Overall, eight simulation scenarios were selected and summarized in Table 4 . The first four scenarios, were intended to investigate the effects of downscaling and the future air quality in the United States. These scenarios are (1) present meteorology with present emissions, (2) present meteorology with future emissions, (3) future meteorology with present emissions and (4) future meteorology with future emissions, which are identical to the scenarios used in Wu et al. (2008b), for GEOS-Chem. While the other four scenarios were combined with the previous four scenarios to study the impacts of change of biogenic emissions (MEGAN2 vs. BEIS3) in the future climate scenarios (2000 and 2050), as shown in grey color.

\section{Discussion and results}

\subsection{Comparison of present and future climate}

Model performance of meteorological outputs was evaluated by comparing the global GCM outputs to the downscaled MM5 outputs. We have chosen the global GCM outputs as the bases of comparison, instead of observational data, for three reasons: (1) the primary focus of the study was to investigate the effects of downscaling, this type of comparison permitted one to quantify the relative air quality impacts from meteorological downscaling; (2) the global GCM outputs used for the comparisons have been extensively evaluated with observational data (Rind et al., 2007; Schmidt et al., 2006). This type of comparison should give sufficient understanding of MM5 performance to the present climate condition; (3) since no observed boundary conditions (i.e., FDDA technique or observation nudging in the GISS GCM) were used to constrain GCM simulations, the characteristics of MM5 outputs are unlikely to follow the hourly/daily trends with the observational data. If model performance was done on monthly averaging, comparing MM5 outputs to the GISS outputs would give sufficient meteorological validation-just as if the outputs had been compared with observational data.

Several climatic variables were selected for the purpose of air quality evaluation: ground temperature $(\mathrm{T})$, relative humidity (RH), precipitation (RAIN), shortwave radiation at the surface (SW), total cloud fraction (CFRACT), wind speed (WSP), wind direction (WDR) and Planetary Boundary Layer (PBL) height from present and future climate conditions. The main focus was placed on temperature since the rise in temperature is expected to worsen the regional air quality in the future by enhancing both biogenic emissions and photochemical reaction rates of gaseous precursors of ozone and secondary $\mathrm{PM}_{2.5}$. In addition to temperature, the change of wind speed and PBL height were also expected to be important to the regional air quality since both affect the rates of horizontal and vertical dispersions. Thus, it is expected to have a significant impact on surface ozone and $\mathrm{PM}_{2.5}$ concentrations if significant changes from these variables are observed (Aw and Kleeman, 2003; Gaza, 1998).

In response to the change of greenhouse gases, the results from regional MM5 show that the future mean surface temperature was projected to increase $1.0-2.0 \mathrm{~K}$ when compared to the present, as shown in Table 5. The major changes of temperature occurred in May-September (MJJAS) for all three domains. The change of mean surface temperature between future and present climate was about $2.0 \mathrm{~K}$ for the 
Table 4. Summary of CMAQ simulations conducted in this study.

\begin{tabular}{|c|c|c|c|c|c|c|}
\hline \multicolumn{3}{|c|}{ Scenario } & \multicolumn{3}{|c|}{ Model } & \multirow[t]{2}{*}{ Scenario index } \\
\hline Meteorology & Anthrop. emission & Bio. emission & GEOS-Chem & CMAQ & CMAQ & \\
\hline 1999-2001 & 2000 & MEGAN2 (1999-2001) & $4^{\circ} \times 5^{\circ}$ & $36 \mathrm{~km} \times 36 \mathrm{~km}$ & $12 \mathrm{~km} \times 12 \mathrm{~km}^{*}$ & 2000M_2000E_M \\
\hline 1999-2001 & 2050 & MEGAN2 (1999-2001) & $4^{\circ} \times 5^{\circ}$ & $36 \mathrm{~km} \times 36 \mathrm{~km}$ & $12 \mathrm{~km} \times 12 \mathrm{~km}^{*}$ & 2000M_2050E_M \\
\hline 2049-2051 & 2000 & MEGAN2 (2049-2051) & $4^{\circ} \times 5^{\circ}$ & $36 \mathrm{~km} \times 36 \mathrm{~km}$ & $12 \mathrm{~km} \times 12 \mathrm{~km}^{*}$ & 2050M_2000E_M \\
\hline 2049-2051 & 2050 & MEGAN2 (2049-2051) & $4^{\circ} \times 5^{\circ}$ & $36 \mathrm{~km} \times 36 \mathrm{~km}$ & $12 \mathrm{~km} \times 12 \mathrm{~km} *$ & 2050M_2050E_M \\
\hline 2000 & 2000 & BEIS3 (2000) & - & $36 \mathrm{~km} \times 36 \mathrm{~km}$ & - & 2000M_2000E_B \\
\hline 2000 & 2050 & BEIS3 (2000) & - & $36 \mathrm{~km} \times 36 \mathrm{~km}$ & - & 2000M_2050E_B \\
\hline 2050 & 2000 & BEIS3 (2050) & - & $36 \mathrm{~km} \times 36 \mathrm{~km}$ & - & 2050M_2000E_B \\
\hline 2050 & 2050 & BEIS3 (2050) & - & $36 \mathrm{~km} \times 36 \mathrm{~km}$ & - & 2050M_2050E_B \\
\hline
\end{tabular}

* Only 2000 and 2050 cases were simulated.

Table 5. Average zonal temperatures of GISS and MM5 outputs for the present and future climate.

\begin{tabular}{|c|c|c|c|c|c|c|c|c|c|c|}
\hline \multirow[b]{2}{*}{ Year } & \multirow[b]{2}{*}{ Type } & \multicolumn{3}{|c|}{ Midwest } & \multicolumn{3}{|c|}{ Northeast } & \multicolumn{3}{|c|}{ Southeast } \\
\hline & & *JFMA & ${ }^{*}$ MJJAS & $*$ OND & *JFMA & *MJJAS & $*$ OND & *JFMA & *MJJAS & ${ }^{*} \mathrm{OND}$ \\
\hline \multirow[t]{3}{*}{1999 to 2001} & GISS $^{+}$ & 276.3 & 295.6 & 279.8 & 283.7 & 297.0 & 286.6 & 290.0 & 299.2 & 290.9 \\
\hline & US36 & 277.5 & 296.2 & 280.8 & 282.4 & 296.5 & 285.7 & 290.8 & 300.1 & 291.8 \\
\hline & $\mathrm{US} 12^{++}$ & - & - & - & - & - & - & 290.8 & 300.1 & 291.7 \\
\hline \multirow[t]{3}{*}{2049 to 2051} & $\mathrm{GISS}^{+}$ & 276.6 & 297.6 & 281.1 & 284.3 & 298.4 & 287.7 & 291.0 & 301.1 & 292.4 \\
\hline & US36 & 278.0 & 298.2 & 282.1 & 283.0 & 298.0 & 286.9 & 291.8 & 302.0 & 293.2 \\
\hline & US12 & - & - & - & - & - & - & 291.7 & 302.1 & 293.0 \\
\hline \multirow[t]{3}{*}{ Future- present } & GISS $^{+}$ & 0.4 & 2.0 & 1.4 & 0.7 & 1.4 & 1.2 & 1.1 & 1.9 & 1.5 \\
\hline & US36 & 0.5 & 2.0 & 1.3 & 0.6 & 1.5 & 1.2 & 1.0 & 1.9 & 1.4 \\
\hline & US12 $2^{++}$ & - & - & - & - & - & - & 0.9 & 2.0 & 1.3 \\
\hline
\end{tabular}

* JFMA is the average value from Jan., Feb, Mar., and Apr.; MJJAS is the average value from May, Jun., Jul., Aug., and Sep.; OND is the average value from Oct., Nov., and Dec. + Resolution of GISS output is $4^{\circ} \times 5^{\circ},++$ Only 2000 and 2050 are simulated.

entire CONUS domain, with the maximum hourly temperature difference of $5-6 \mathrm{~K}$ within the $36 \mathrm{~km}^{2}$ grid. These values shown in Table 5 are similar in magnitudes to previous studies reported in the literature, where a larger increase in temperature was projected for the Midwest and Southeast, with a smaller increase expected for the Northeast (i.e., average +1 K) (Bell et al., 2007; Nolte et al., 2008; Zhang et al., 2008). The increase in temperature across the United States potentially enhances the rates of radical production and photochemical reaction, thus worsen the ozone and $\mathrm{PM}_{2.5}$ air quality in the future (Aw and Kleeman, 2003; Tai et al., 2010). The comparison of the GISS outputs to the MM5-36 km have shown that the Root Mean Square Error (RMSE) is about $+0.3 \mathrm{~K}$ or less for the CONUS domain, with $\pm 0.6 \mathrm{~K}$ of winter bias and $\pm 0.2 \mathrm{~K}$ summer bias on the defined domains. Based on the value reported by Dawson et al. (2008), the difference of $0.2 \mathrm{~K}$ would translate into about $0.1-0.2$ ppbv increase of surface ozone. With a $0.3 \mathrm{~K}$ difference found between the GISS and MM5 outputs, the effect of downscaling would contribute an additional $0.2-0.3 \mathrm{ppbv}$ of surface ozone in the Northeast domain for the future sce- nario. For downscaling from the MM5-36 km to the MM5$12 \mathrm{~km}$, no significant changes were found on the average and maximum domain-wide temperatures for the Southeast.

The higher future temperature may promote higher ozone and $\mathrm{PM}_{2.5}$ concentrations. The possible changes of PBL height and surface wind speed may also affect the regional air circulations and cause changes of ozone and $\mathrm{PM}_{2.5}$, which need further investigation. From MM5 comparison, the mean surface wind speeds between present and future climate conditions were similar for all domains, with the maximum difference of $0.4 \mathrm{~m} \mathrm{~s}^{-1}$ occurring in the Southeast during MJJAS. The overall annual RMSE was about $0.2 \mathrm{~m} \mathrm{~s}^{-1}$ across the CONUS domain. The mean values of wind speeds during MJJAS were $2.6 \mathrm{~m} \mathrm{~s}^{-1}, 3.0 \mathrm{~m} \mathrm{~s}^{-1}$ and $2.7 \mathrm{~m} \mathrm{~s}^{-1}$ for the Midwest, Northeast and Southeast, respectively. Although similar mean values of wind speeds between present and future climate conditions were observed, a clear indication of intensification of horizontal dispersion at the high wind speed portion (i.e., $6 \mathrm{~m} \mathrm{~s}^{-1}$ or above) were also found in the cumulative distribution curve (CDF) in the Northeast and Midwest domains for the future. These phenomena would not likely 


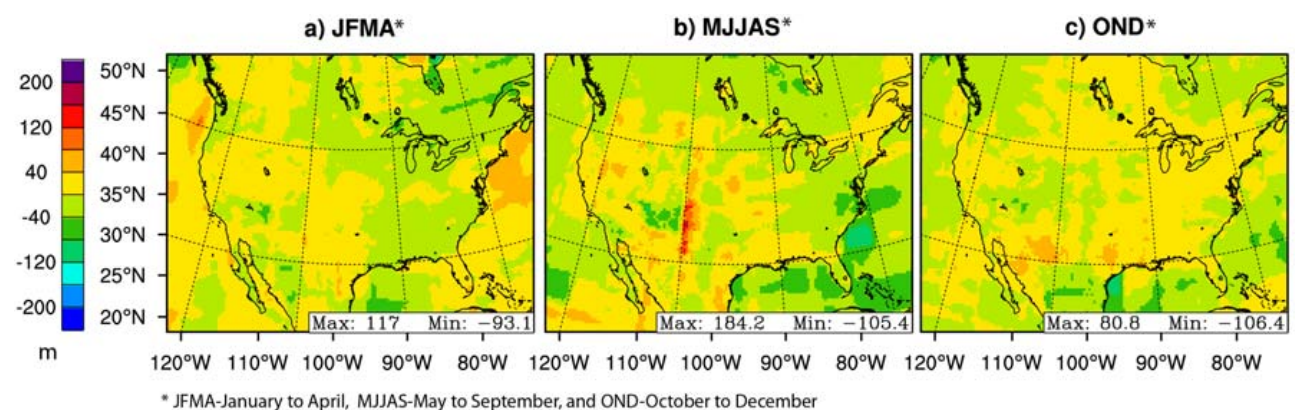

Fig. 3. Average seasonal change in PBL height difference between 2049-2051 and 1999- 2001 from MM5 outputs: (a) JFMA, (b) MJJAS, and (c) OND.

increase the ozone and $\mathrm{PM}_{2.5}$ concentrations in the future since ozone and $\mathrm{PM}_{2.5}$ are formed at a low wind speed condition. Therefore, it is concluded that the change of wind speed between present and future climate conditions has a minor effect on the ozone and $\mathrm{PM}_{2.5}$ air quality on the three domains. For the downscaling perspective, a large difference (i.e., $0.6 \mathrm{~m} \mathrm{~s}^{-1}$ ) was found between the GISS and MM5$36 \mathrm{~km}$ outputs in the Midwest. The difference was caused by the inconsistencies of terrain elevation and grid resolution between GISS GCM and MM5 in the Rocky Mountain area where significant change in elevation was observed. This difference in wind speed may introduce significant biases to the future air quality in the Midwest when comparing GEOS-Chem outputs to CMAQ outputs. Figure $3 \mathrm{a}-\mathrm{c}$ show the average change in PBL heights between present and future climate conditions during January-April (JFMA), May-September (MJJAS), and October-December (OND), respectively. It is observed that most of the places in the United States show a minor change of PBL height, except for the Western United States during the months of MJJAS. The maximum difference of PBL height between present and future climate conditions ranged from $-190 \mathrm{~m}$ to $305 \mathrm{~m}$. In the study domains, no significant change of PBL height $( \pm 5 \%$ difference) was found to be attributable to climate change. These findings are consistent with the GISS's results, where only $\pm 10 \%$ PBL changed for the future year scenario (Mickley et al., 2006; Wu et al., 2008a).

In addition to wind speed and PBL height, other meteorological parameters such as solar radiation, humidity, and precipitation may also affect the ozone and $\mathrm{PM}_{2.5}$ air quality. Our findings show that the future temperature will increase by at least $2 \mathrm{~K}$. This increase in temperature may be linked to the increase of solar radiation at the surface (a direct proportional relationship between temperature and solar radiation is generally expected). In the Midwest, more solar radiation is predicted reaching the surface due to the decrease of cloud cover. The increase in temperature with less cloud cover in the Midwest may potentially result in a significant increase of ozone under the future climate condition. In contrast, in the Northeast and Southeast, the solar radia- tion will decrease by $10 \%$ due to an increase of cloud cover in the future climate conditions. Although the average temperatures are increased by 1.0 to $2.0 \mathrm{~K}$, the increase of cloud cover may limit the amount of solar radiation reaching the surface and possibly result in less ozone formation in these two regions. For precipitation, a slight change was found for the three regions. The seasonal averages of precipitation (JFMA, MJJAS, and OND) are within a $0.01 \mathrm{~cm}$ rainfall difference (Gustafson Jr. and Leung, 2007). From geospatial plots (not shown), a slight increase in precipitation was observed in both Northeast and Southeast regions and a slight decrease in precipitation was observed in the Midwest. For relative humidity $(\mathrm{RH})$, the overall changes are about $\pm 5 \%$ from present to future climate conditions among different time periods and domains. A slight increase of moisture was observed in the Northeast, while slight decreases were found in the Midwest and Southeast. The average relative humidity in the Southeast was much higher than in the Midwest and Northeast. On average, it was about 10 and $15 \%$ higher. The average $\mathrm{RH}$ in the future condition during MJJAS was about 80, 75, and $55 \%$ for the Southeast, Northeast, and Midwest, respectively. The high RH possibly enhances chemical deposition rates of $\mathrm{SO}_{2}$ and also promotes precipitation (Sakamoto et al., 2004). For the downscaling perspective, a large difference of RH is observed between the GISS and MM5-36 km outputs. We have estimated an average of $10 \%$ increase of moisture across different domains from downscaling the global model into the regional model. For the MM5-36 km to MM5-12 km outputs, only less than a $1.0 \%$ in difference of RH is observed. The large difference in RH observed between the GISS and MM5-36 km outputs was introduced by the inconsistence of advection schemes and vertical layer structures used by those two climate models. The additional RH in MM5 may help the formation of clouds by causing air to increase their elevation and promote more precipitation (Gustafson Jr. and Leung, 2007; Gilliam et al., 2006; Queen et al., 2008). 
a) $\mathrm{MDAl} \mathrm{O}_{3}$

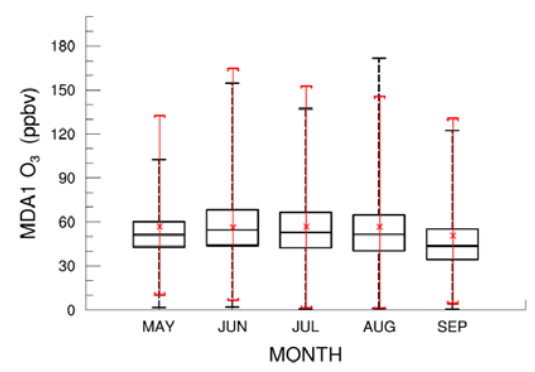

b) $\mathrm{MDA} 8 \mathrm{O}_{3}$

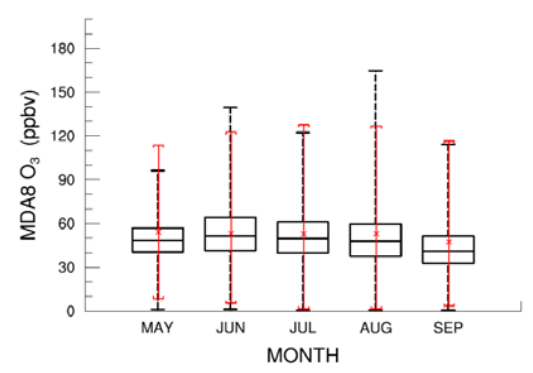

Fig. 4. Statistical distributions of ozone concentrations for the months of MJJAS in 1999-2001: (a) maximum 1-h (MDA1), and (b) 8-h average ozone (MDA1). The black color corresponds to the 1999-2001 CMAQ simulated value, where as the red color represents the CASTNET observed values from 1998 to 2002.

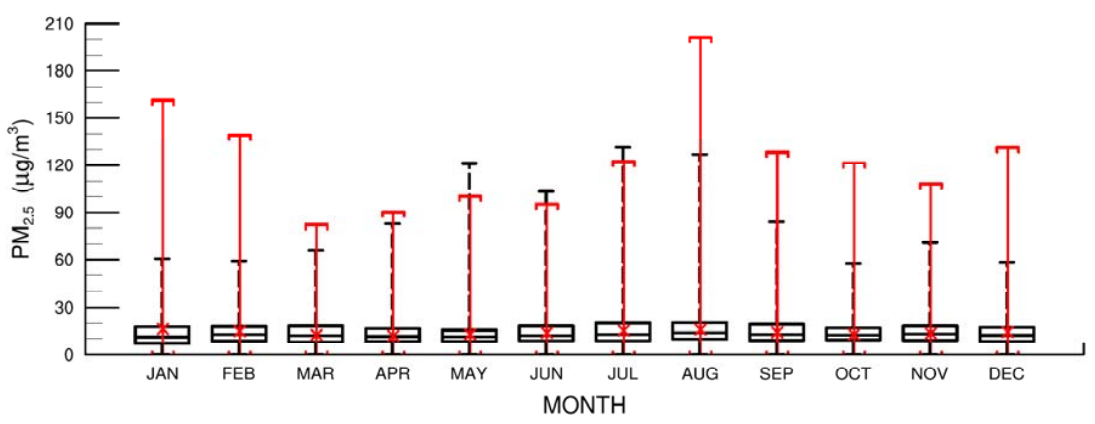

Fig. 5. Monthly statistical distributions of $\mathrm{PM}_{2.5}$ concentrations for year 1999-2001. The black color corresponds to the 1999-2001 CMAQ simulated values, where as the red color represents the CASTNET observed values from 1998 to 2002.

\subsection{Comparisons of present climate air quality using MEGAN2 emissions}

The qualitative evaluation of CMAQ chemical predictions for the present climate condition was conducted by comparing the average observed quantities of ozone and $\mathrm{PM}_{2.5}$ from the Clean Air Status and Trends Network (CASTNET) http://www.epa.gov/CASTNET/) and the Speciation Trends Network (STN). The results provided some level of agreement between the observed and our simulated values to justify the use of CMAQ results in representing the future air quality. Due to the difference in meteorological inputs, the hourly comparison was not performed, instead average monthly values were used. Figure $4 \mathrm{a}$, b show the statistical distributions of maximum daily 1-h and 8-h average $\mathrm{O}_{3}$ concentrations simulated for the months of MJJAS in 19992001. The black and red colors correspond to the 1999-2001 CMAQ simulated value and the CASTNET observed value from 1998-2002, respectively. The dashed lines at the top and bottom of each box plot show the maximum and minimum values for the data. The square box specifies the $\mathrm{O}_{3}$ values of 75,50 , and $25 \%$ tiles and the cross mark shows the monthly mean value. The maximum 1 -h and $8-\mathrm{h} \mathrm{O}_{3}$ concentrations are well reproduced with the mean ozone values slightly under predicted. The average monthly value of $\mathrm{O}_{3}$ is about 50 to $60 \mathrm{ppbv}$. The good agreement of $\mathrm{O}_{3}$ suggests that the $\mathrm{CO}$ and NOx emissions used in this study were relatively close to the actual measured emissions from those five years (Zhang et al., 2008). Our simulated $\mathrm{O}_{3}$ concentrations were 5-10\% lower than the observed values, which is comparable with the results reported by Zhang et al. (2008) and Tagaris et al. (2007) where $2-15 \%$ different in $\mathrm{O}_{3}$ prediction from 2000 to 2002 (June to August).

Figure 5 shows the comparison of monthly average $\mathrm{PM}_{2.5}$ from CMAQ outputs and the STN observational network. Identical labeling conventions were used in Fig. 5, as was used in Fig. 4. Once again, the average $\mathrm{PM}_{2.5}$ concentration in CMAQ was slightly under predicted for most of the months. As expected, the peak values of $\mathrm{PM}_{2.5}$ between simulated and observed values do not match well due to the fact that conservative emissions have been used in the simulation where no special event (such as a large fire or volcanic eruption) was included in the present emissions. Since the maximum $\mathrm{PM}_{2.5}$ value is either lower or close to the maximum observed value, the CMAQ outputs reproduce reasonably well on the present $\mathrm{PM}_{2.5}$ level. For the underestimate of $\mathrm{PM}_{2.5}$, Zhang et al. (2008) and Tagaris et al. (2007) suggest that the under prediction in the current version of CMAQ was caused by low aerosol yields, higher vapor pressures, 
a) Midwest

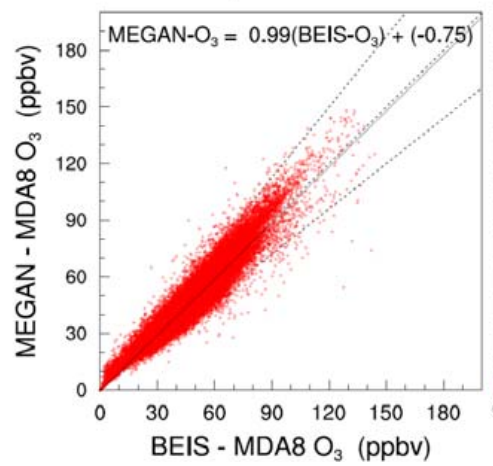

b) Northeast

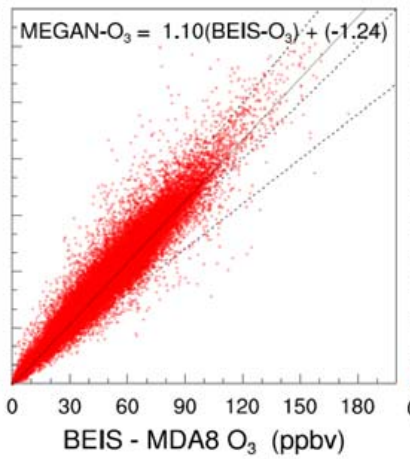

c) Southeast

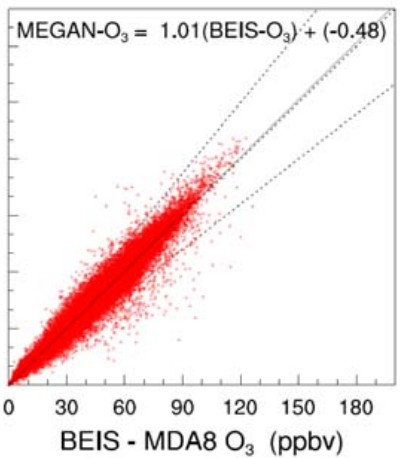

Fig. 6. Scatter plots of MEGAN2-MDA8 ozone versus BEIS3-MDA8 ozone for the months of May-September in the year 2000 on: (a) Midwest, (b) Northeast, and (c) Southeast.

and a lack of isoprene SOA treatment, which accounts for $0.01-1.52 \mu \mathrm{g} \mathrm{m}^{-3}$ of $\mathrm{PM}_{2.5}$.

\subsection{Comparisons of CMAQ simulated outputs (MEGAN2 vs. BEIS3 inventories)}

As mentioned earlier, the MEGAN2 biogenic model estimated about $50 \%$ higher isoprene emission than the BEIS3 biogenic model. However, due to the fact that the BEIS3 model estimated higher emissions on other biogenic emissions such as terprene and formaldehyde, the resulting difference of total annual biogenic emissions between those two models has turned into about $5 \%$. In summer, isoprene emission contributed a large portion of overall biogenic emissions and resulted in higher overall biogenic emissions in MEGAN2. Conversely, the influence of isoprene emission was diminishing when winter approached which resulted in lower overall emissions in MEGAN2. To investigate the impacts of using different biogenic models in the climate change study, both MEGAN2 and BEIS3 biogenic emissions were used to simulate both 2000 and 2050 using CMAQ. Figure $6 \mathrm{a}-\mathrm{c}$ show the MDA8 ozone of CMAQ-MEGAN2 vs. CMAQ-BEIS for the months of May-September in the year 2000 on the Midwest, Northeast, and Southeast, respectively. The CMAQ-MEGAN2 represents the CMAQ simulation using MEGAN2 biogenic emissions, where as the CMAQBEIS3 denotes the CMAQ simulation using BEIS3 biogenic emissions.

Both Midwest and Southeast show only a minor difference in MDA8 ozone between MEGAN2 and BEIS3. The slopes of those two best-fit curves are close to one, which signifies that the Midwest and Southeast are insensitive to the increase of VOC emissions. Table 6 shows the percentage change of MDA8 ozone and $\mathrm{PM}_{2.5}$ in the present (2000) and future (2050) climate conditions. For ozone, the differences between 2000 and 2050 on the Midwest and Southeast were less than $1.0 \%$ (e.g., $|(-1.4)-(-0.6)|=-0.8$ ), which implied that the impacts of change of biogenic emissions are indepen- dent from the selection of simulation year since both years of CMAQ simulations responded similarly. In the Northeast, $10 \%$ increase (based on the best-fit line) of MDA8 ozone is observed (shown in Fig. 6b). The increase of MDA8 ozone implies that the Northeast region is perhaps made up from multiple VOC-limited sub-regions. As discussed by Duncan et al. (2009), the Northeastern region of the US, such as New York and other metropolitan areas, was a typical radical-limited/VOC-limited region (Kleinman et al., 2000). There is no doubt that the majority of places in the Northeast are more radical-limited/VOC-limited conditions due to a large portion of urban land (Milford et al., 1994; Milford et al., 1989). As with the increase of biogenic emissions in the Northeast domain, the VOC-limited sub-regions within the domain have led to the increase of MDA8 ozone. In this study, it was observed that the average changes of MDA8 ozone on the Northeast domain in 2000 and 2050 are $5.4 \%$ and $6.0 \%$, respectively, as shown in Table 6 .

For $\mathrm{PM}_{2.5}$, Fig. 7 shows the chemical breakdown of annual average $\mathrm{PM}_{2.5}$. The left side of the figure shows the constituent of $\mathrm{PM}_{2.5}$ and the right side of the figure shows the organic carbon (OC) portion of $\mathrm{PM}_{2.5}$. The suffix of "-B" and "-M" indicate the BEIS3 and MEGAN2 inventories were used in the CMAQ simulations, respectively. The overall changes of $\mathrm{PM}_{2.5}$ between the MEGAN2 and BEIS3 emissions were estimated to be about $-5,-3$, and $-6 \%$ for the Midwest, Northeast, and Southeast, respectively (shown on the right side of the figure); The largest portion of change in $\mathrm{PM}_{2.5}$ concentration was observed in the organic aerosol. The impact of $\mathrm{PM}_{2.5}$ in the Southeast domain was much larger than the Midwest and Northeast due to a large difference in isoprene emission between those two biogenic models in the Southeast.

To investigate the seasonal impacts of $\mathrm{PM}_{2.5}$, the annual CMAQ outputs have been divided into JFMA, MJJAS, and OND. As shown in Table 6 (last two columns), large changes of $\mathrm{PM}_{2.5}$ were observed in the months of JFMA 
Table 6. The percentage change of MDA8 ozone (in ppbv) and $\mathrm{PM}_{2.5}$ (in $\mu \mathrm{g} \mathrm{m}^{-3}$ ) in 2000 and 2050.

\begin{tabular}{|c|c|c|c|c|c|c|c|c|}
\hline & \multirow[b]{2}{*}{ Year } & & \multicolumn{2}{|c|}{ Slope } & \multicolumn{2}{|c|}{ Intercept } & \multirow{2}{*}{$\begin{array}{c}\text { (MEGAN2-BEIS3) } \\
\text { /MEGAN2 } \\
2000\end{array}$} & \multirow{2}{*}{$\begin{array}{c}\text { (MEGAN2-BEIS3) } \\
\text { /MEGAN2 } \\
2050\end{array}$} \\
\hline & & & 2000 & 2050 & 2000 & 2050 & & \\
\hline \multirow{3}{*}{ MDA8 ozone } & *MJJAS & Midwest & 0.99 & 1.02 & -0.1 & 1.4 & $-1.4 \%$ & $-0.6 \%$ \\
\hline & & Northeast & 1.1 & 1.11 & -1.3 & -1.5 & $5.4 \%$ & $6.0 \%$ \\
\hline & & Southeast & 1 & 1 & -0.1 & -0.1 & $0.1 \%$ & $-0.6 \%$ \\
\hline \multirow{9}{*}{$\mathrm{PM}_{2.5}$} & *JFMA & Midwest & 0.97 & 0.97 & -0.2 & -0.2 & $-3.5 \%$ & $-4.0 \%$ \\
\hline & & Northeast & 0.98 & 0.97 & 0.0 & 0.0 & $-3.3 \%$ & $-2.6 \%$ \\
\hline & & Southeast & 0.92 & 0.92 & -0.1 & 0.0 & $-4.3 \%$ & $-5.5 \%$ \\
\hline & *MJJAS & Midwest & 1.01 & 1 & -0.4 & -0.3 & $-1.7 \%$ & $-2.1 \%$ \\
\hline & & Northeast & 1 & 1 & 0.0 & -0.1 & $-0.3 \%$ & $-0.3 \%$ \\
\hline & & Southeast & 0.97 & 0.96 & -0.2 & -0.2 & $-1.6 \%$ & $-2.2 \%$ \\
\hline & *OND & Midwest & 0.98 & 0.97 & -0.3 & -0.3 & $-6.3 \%$ & $-6.0 \%$ \\
\hline & & Northeast & 0.98 & 0.98 & 0.0 & 0.0 & $-4.2 \%$ & $-4.3 \%$ \\
\hline & & Southeast & 0.93 & 0.9 & -0.1 & 0.0 & $-6.6 \%$ & $-7.4 \%$ \\
\hline
\end{tabular}

* JFMA is the average value from Jan., Feb, Mar., and Apr.; MJJAS is the average value from May, Jun., Jul., Aug., and Sep.; OND is the average value from Oct., Nov., and Dec.

Table 7. Summary of MDA8 ozone (in ppbv) from CMAQ outputs and the concentration differences between CMAQ and GEOS-Chem for the present and future climate.

\begin{tabular}{|c|c|c|c|c|c|c|c|c|c|}
\hline \multirow[t]{2}{*}{ MDA8 type } & \multirow[t]{2}{*}{ Domain } & \multicolumn{2}{|c|}{ 2000M_2000E } & \multicolumn{2}{|c|}{ 2000M_2050E } & \multicolumn{2}{|c|}{ 2050M_2000E } & \multicolumn{2}{|c|}{ 2050M_2050E } \\
\hline & & CMAQ & CMAQ-GC* & CMAQ & CMAQ-GC* & CMAQ & CMAQ-GC* & CMAQ & CMAQ-GC* \\
\hline \multirow[t]{4}{*}{$\operatorname{Max}^{* *}$} & MW & 149 & +43 & 125 & +36 & 165 & +53 & 139 & +44 \\
\hline & $\mathrm{NE}$ & 182 & +68 & 168 & +69 & 186 & +60 & 164 & +57 \\
\hline & $\mathrm{SE}-36 \mathrm{~km}$ & 138 & +34 & 133 & +51 & 138 & +38 & 129 & +48 \\
\hline & $\mathrm{SE}-12 \mathrm{~km}$ & 154 & $* * *$ & 145 & $* * *$ & 178 & $* * *$ & 163 & $* * *$ \\
\hline \multirow[t]{4}{*}{ Avg ${ }^{* *}$} & MW & 54 & +2 & 49 & 0 & 56 & +2 & 51 & +1 \\
\hline & NE & 57 & -9 & 50 & -11 & 59 & -11 & 53 & -9 \\
\hline & SE-36 km & 55 & -10 & 51 & -4 & 56 & -8 & 52 & -1 \\
\hline & SE-12 km & 51 & $* * *$ & 46 & $* * *$ & 51 & $* * *$ & 48 & $* * *$ \\
\hline
\end{tabular}

${ }^{*}$ GC stands for GEOS-Chem. Domain averages in GC are based on results from $4^{\circ} \times 5^{\circ}$ resolution outputs. ${ }^{* *}$ Max - domain-maxima; Avg - domain-averaged. ${ }^{* * *}$ Not available.

and OND for all three domains, while insignificant change of $\mathrm{PM}_{2.5}$ was found in MJJAS. The largest change of slope, with the value of 0.93 , was observed in the Southeast in the months of OND. This value indicates the $\mathrm{PM}_{2.5}$ estimates of CMAQ-MEGAN2 are about $7 \%$ lower than the estimates of CMAQ-BEIS3. This $-7 \%$ difference translates into about $-2 \mu \mathrm{g} \mathrm{m}^{-3}$ on average. The lower $\mathrm{PM}_{2.5}$ in CMAQ-MEGAN2 was mainly contributed by the lower terprene emission from MEGAN2 inventories; since terprene emission undergoes oxidation to form condensable gases and eventually converts into secondary organic aerosols (SOAs). In the CMAQ simulations, we are aware of the fact that parts of the SOAs pathway for isoprene was missing in the present CMAQ configuration, which might result in lower isoprene SOAs on both CMAQ-MEGAN2 and CMAQ-BEIS3. It is expected that the difference in isoprene emissions between CMAQ-MEGAN2 and CMAQ-BEIS3 in the months of JFMA and OND was fairly small, so the impacts of iso- prene pathway were neglectable. However, for MJJAS, a larger impact from the missing isoprene pathway was expected due to the fact that isoprene emission is the dominant species in the biogenic VOC and large differences of VOC emissions were observed between CMAQ-MEGAN2 and CMAQ-BEIS3. Zhang et al. (2008) and Boylan et al. (2005) suggested the maximum impact of lacking of isoprene pathway in CMAQ was about $1.52 \mu \mathrm{g} \mathrm{m}^{-3}$ and $2.2 \mu \mathrm{g} \mathrm{m}^{-3}$ of SOAs, respectively. Nevertheless, since the focus of the $\mathrm{PM}_{2.5}$ discussion has been placed on the months of JFMA and OND, the impact of SOAs from isoprene may be ignored. For different climate conditions, very minor differences (i.e., less than $1.0 \%$ ) were observed between 2000 and 2050 as shown in the last two columns of Table 6. Once again, this indicates that the impact of change of biogenic emissions is independent from climate conditions since the CMAQ simulation results responded in the same way on both years. 


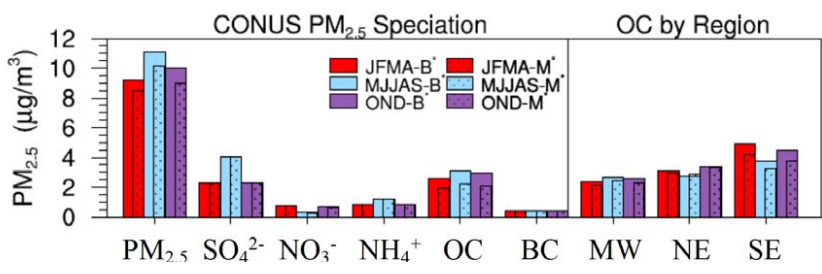

Fig. 7. The annual average of $\mathrm{PM}_{2.5}$ in the CONUS domain (left), and the annual average organic carbon of $\mathrm{PM}_{2.5}$ for the Midwest, Northeast, and Southeast.

\subsection{Future ozone air quality and comparison of CMAQ vs. GEOS-Chem}

To better understand future air quality, both CMAQ and GEOS-Chem outputs were analyzed to investigate the future air quality trends. As mentioned earlier, both models used the same US NEI inventories, future emissions projection factors, and meteorological fields from GISS'III GCM. Although the inputs from those models were kept consistent throughout implementations, it was expected that the model outputs might still give an inconsistent prediction of future air quality due to the differences in resolutions, chemical mechanisms, and model sensitivity to climate change. Table 7 shows the summary of MDA8 ozone outputs from CMAQ and the concentration differences between CMAQ and GEOS-Chem. The four scenarios used in the simulations were: (1) 1999-2001 meteorology condition with 1999-2001 present emissions (2000M_2000E), (2) 19992001 meteorology condition with 2049-2051 future emissions (2000M_2050E), (3) 2049-2051 meteorology condition with 1999-2001 present emissions (2050M_2000E), and (4) 2049-2051 meteorology condition with 2049-2051 future emissions (2050M_2050E). It should be noted that all simulations presented in this section are the simulations using MEGAN2 biogenic emissions and the same notation will be used throughout this manuscript. As reported by $\mathrm{Wu}$ et al. (2008b), the GEOS-Chem projected a 2.0-5.0 ppbv increase of domain-averaged MDA8 ozone over the Midwest and Northeast domains, and a little change over the Southeast domain due to climate change. For CMAQ, an increase of domain-averaged MDA8 ozone by about 1.0 $3.0 \mathrm{ppbv}$ (i.e., calculated by taking the average difference between 2049-2051 (2050M) and 1999-2001 (2000M)) were projected from climate change for all domains. These results are similar to the findings reported by Zhang et al. (2008), Hogrefe et al. (2004), and Racherla and Adams (2008). It is expected that our results may predict less increase of the MDA8 ozone than the other findings since the selected IPCC scenario (i.e., A1B) predicts less future warming than the A2 scenario from Hogrefe, et al. (2004) and Racherla and Adams (2009).

Large discrepancies of domain-averaged MDA8 ozone between CMAQ and GEOS-Chem were observed in the North- east and Southeast domains, where the CMAQ values were consistently lower than the GEOS-Chem (see in Table 7 at the column CMAQ-GC*). In the comparison of GEOSChem and CMAQ outputs, we observed that GEOS-Chem predicted higher minimum ozone than CMAQ. Conversely, it also predicted lower maximum ozone than CMAQ due to the restriction of grid resolution $\left(4^{\circ} \times 5^{\circ}\right)$. The minimum and maximum ozone concentrations in GEOS-Chem were at the range of $15-20 \mathrm{ppbv}$ and $75-125 \mathrm{ppbv}$, whereas the maximum and minimum values in CMAQ were at $3-5$ ppbv and $130-180 \mathrm{ppbv}$, respectively. These discrepancies is partially contributed by the lack of lightning emissions in CMAQ since we did not implement lightning as a source of $\mathrm{NO}_{\mathrm{x}}$ in the upper troposphere for either the present or future climate condition. Allen et al. (2010) suggested that the enhancement of MDA8 from lightning NOx could be up to $2.5 \mathrm{ppbv}$ in the Northeast and $5.0 \mathrm{ppbv}$ in the Southeast domain. Moreover, the difference in the sensitivity of ozone under the coarse grid resolution, the different chemical mechanisms used in the models, and the different in the meteorological parameters (i.e., PBL), may also contribute to the discrepancies. It is predicted that increasing the grid resolution in GEOS-Chem may reduce a portion of the discrepancy of MDA8 ozone between GEOS-Chem and CMAQ.

For the perspective of the climate change, both models consistently projected an increasing response of surface MDA8 ozone from climate change on the Northeast and Midwest domains. The average effects on climate change are about $+1.0-2.5 \mathrm{ppbv}$ and $+2.0-2.5 \mathrm{ppbv}$ for GEOS-Chem and CMAQ, respectively, whereas the average effects from reducing emissions are $+4.0-7.0 \mathrm{ppbv}$ and $+5.0-7.0 \mathrm{ppbv}$. It is clear that emissions have stronger impacts than the climate change in the regional air quality. In the southeast domain, inconsistent MDA8 ozone between GEOS-Chem and CMAQ was observed, where GEOS-Chem was insensitive to climate change and CMAQ had a minor increase of the MDA8 ozone (e.g., future ozone subtracted by present ozone). We believed that the different treatment between the models in the isoprene nitrate should not be the major contributor of such differences since both models did not implement recycling of $\mathrm{OH}$ from photo-decomposition of isoprene nitrate. Instead, the differences in implemented chemical mechanisms and grid resolution between the models caused the actual different.

To further investigate the difference between CMAQ and GEOS-Chem on the MDA8 ozone, the cumulative distribution functions (CDF) were constructed for all four simulated scenarios. These are shown in Fig. 8. The black, green, red, and blue colors represent the scenarios of 2000M_2000E, 2000M_2050E, 2050M_2000E, and 2050M_2050E, respectively. It is observed that CMAQ and GEOS-Chem performed quite similarly in the Northeast and Midwest domains, where the order of the color lines were identical. Distinct separation between the colored lines found in Fig. 8a, b, d, e, demonstrates a discrete relationship was 


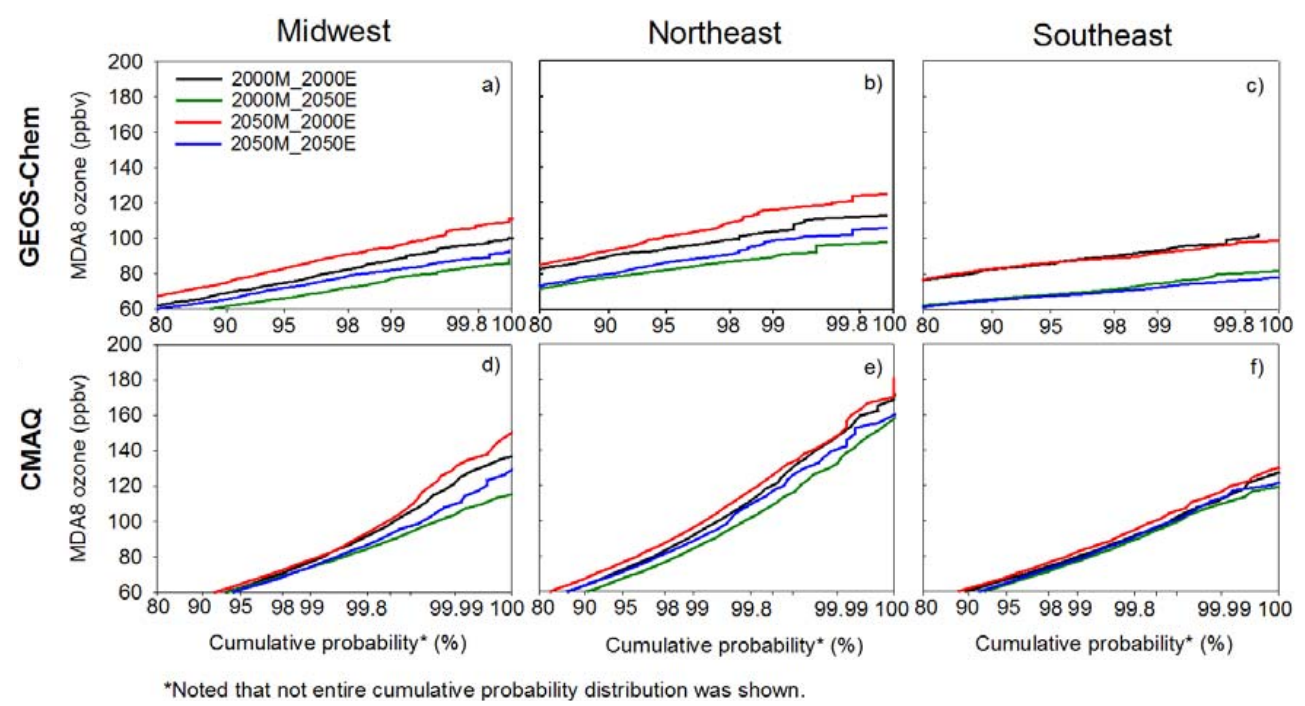

Fig. 8. The cumulative probability function of MDA8 ozone for GEOS-Chem and CMAQ: (a) Midwest for GEOS-Chem, (b) Northeast for GEOS-Chem, (c) Southeast for GEOS-Chem, (d) Midwest for CMAQ, (e) Northeast for CMAQ, and (f) Southeast for CMAQ.

developed among the scenarios. The non-linearity (skew) distribution (e.g., Fig. 8d) indicates a small value of high ozone concentration was found in the CDF. It should be noted when a line is far more up and left, it implied a higher MDA8 ozone distribution has been found. As expected, the order of lines were red, black, blue, and green, and the worst MDA8 ozone air quality occurs in the red line, which corresponds to the future scenario (2049-2051 meteorological conditions with 1999-2001 present emissions) where higher overall temperature with no emissions control. Since the reduction of emissions was a stronger factor than the increase of temperature from climate change, we would expect that the red and black lines should be more in the up and left position. In the Southeast domain, shown in Fig. 8c and f, the order of the colored lines is somewhat different between GEOS-Chem and CMAQ. In GEOS-Chem (Fig. 8c), the colored lines (red vs. black and green vs. blue) are virtually overlapping and consequently not able to demonstrate the effect of climate change. Conversely, in CMAQ (Fig. 8f), clear separations were found among those lines and the effect of climate change was observed. As mentioned earlier, the inconsistency of the results between GEOS-Chem and CMAQ may relate to differences in chemical mechanism and resolution $\left(4^{\circ} \times 5^{\circ}\right.$ vs. $\left.36 \mathrm{~km} \times 36 \mathrm{~km}\right)$.

For the comparison between $36 \mathrm{~km}$ and $12 \mathrm{~km}$ CMAQ simulations in the Southeast, 4-5 ppbv of differences in average MDA8 ozone were found in present and future climate conditions. Since both climate conditions exhibited the same amount of differences, the relationship between the present and future climate on average MDA8 ozone remained the same. On the other hand, significant changes of maximum MDA8 ozone between $36 \mathrm{~km}$ and $12 \mathrm{~km}$ CMAQ were observed, where the average differences were $15 \mathrm{ppbv}$ for the present climate and $36 \mathrm{ppbv}$ for the future climate. Overall, the results suggested that it is important to use a finer resolution when local maximum MDA8 is concerned. Otherwise, the $36 \mathrm{~km}$ resolution should be sufficient for evaluating the future climate trends if the average MDA8 ozone is used.

\subsection{Future $\mathbf{P M}_{2.5}$ air quality}

For $\mathrm{PM}_{2.5}$, no comparison between GEOS-Chem and CMAQ will be presented since parts of the secondary organic species and the breakdown of $\mathrm{PM}_{2.5}$ and $\mathrm{PM}_{2.5 t o 10}$ were missing from GEOS-Chem v7.03.06. In CMAQ, the 1-h maximum and annual average $\mathrm{PM}_{2.5}$ among different domains and scenarios were ranged from 96.1 to $127 \mu \mathrm{g} \mathrm{m}^{-3}$ and 4.5 to $11.7 \mu \mathrm{g} \mathrm{m}^{-3}$, respectively. It was observed that the effect of climate change had only a minor impact on the future $\mathrm{PM}_{2.5}$ concentration, whereas the reduction of emissions contributed a significant reduction of $\mathrm{PM}_{2.5}$. The total $\mathrm{PM}_{2.5}$ reductions from present to future was estimated to be about 40 to $50 \%$, in which the average $\mathrm{PM}_{2.5}$ concentrations from the present climate (average of 2000M_2000E and $2000 \mathrm{M} 2050 \mathrm{E}$ ) and the future climate (average of 2050M_2000E and 2050M_2050E) are 8.5-11.5 $\mu \mathrm{g} \mathrm{m}^{-3}$ and $4.5-7.0 \mu \mathrm{g} \mathrm{m}^{-3}$, respectively. For the comparison between $36 \mathrm{~km}$ and $12 \mathrm{~km}$ CMAQ simulations, no difference in $\mathrm{PM}_{2.5}$ was found on the future climate trends (not shown). Figure 9 shows the chemical breakdown of $\mathrm{PM}_{2.5}$. It is observed that a large portion of $\mathrm{PM}_{2.5}$ in CMAQ simulations were coming from sulfate aerosols (SA) and organic aerosols (OA). For organic aerosol, no significant change of OA in the future scenario (T4 or 2050M_2050E) was found. Although researchers have suggested that the increase of temperature might discourage the formation of aerosols by increasing the 


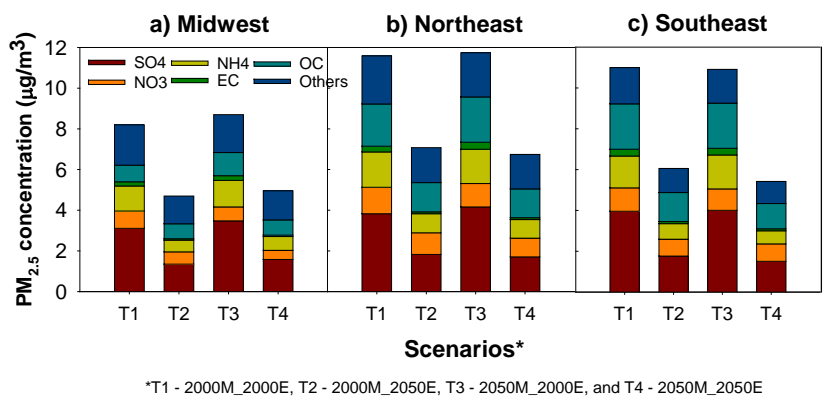

Fig. 9. The chemical breakdown of annual average $\mathrm{PM}_{2.5}$ in CMAQ for: (a) Midwest, (b) Northeast, and (c) Southeast.

rate of vaporization (Zhang et al., 2008), a $5 \%\left(1 \mu \mathrm{g} \mathrm{m}{ }^{-3}\right)$ increase of organic aerosols were still found. This result is similar/comparable to the founding reported by Heald et al. (2008) on the 2100 IPCC A1B scenario, where the annual global change of surface $\mathrm{PM}_{2.5}$ is increased by 5-25\%. For sulfate aerosols, a significant reduction of $\mathrm{SO}_{4}^{2-}$ was observed in the future scenario due to the large anticipated reduction of $\mathrm{SO}_{2} / \mathrm{SO}_{4}$ emissions. The total reduction of sulfate aerosols was around $50 \%$. It is believed that the reduction of $\mathrm{SO}_{4}^{2-}$ aerosols allows more radicals to be used for the formation of $\mathrm{NO}_{3}^{-}$aerosols. However, since the emission of nitrogen oxides was also reduced significantly, the effect from extra radicals have been diminished by the reduction of $\mathrm{NO}_{\mathrm{x}}$ and yielded an overall $5 \%$ reduction of nitrate aerosols. As a result, the overall change of $\mathrm{PM}_{2.5}$ from present condition (T1, 2000M_2000E) to future condition (T4, 2050M 2050E) maintained at about $-40 \%$ to $-50 \%$ and the effect of climate change contributed about $10 \%$ change of $\mathrm{PM}_{2.5}$, whereas the emissions accounted for about $90 \%$ of the change of overall $\mathrm{PM}_{2.5}$.

\section{Conclusions}

The CMAQ simulations on the climate change scenarios were performed using MEGAN2 and BEIS3 biogenic emissions. We found that there was a general increase of MDA8 ozone by about 10 to $12 \%$ in the Northeast domain when using MEGAN2 biogenic emissions. No significant effect was found in the Midwest and Southeast domains. The change of MDA8 ozone in the Northeast domain was mainly triggered by the nature of the VOC-limited region of the domain. For $\mathrm{PM}_{2.5}$, all three domains showed an increase of organic aerosols by $15 \%$ from using MEGAN2 biogenic emissions. Since the CMAQ version used in this study did not include the pathway of isoprene aerosols, it was expected that the $\mathrm{PM}_{2.5}$ results may have been $1-2 \mu \mathrm{g} \mathrm{m}^{-3}$ lower than if the isoprene chemistry had been present. Moreover, since a strong increase of isoprene emission was observed in MEGAN2 in the future climate condition while it was absent from BEIS3, it might have also underestimated the impact of $\mathrm{PM}_{2.5}$ when comparing the difference between MEGAN2 and BEIS3 simulations. Nevertheless, the change of biogenic emissions was not strong enough to alter the relationship among different climate scenarios on both ozone and $\mathrm{PM}_{2.5}$. Therefore, it is concluded that the relationships among different climate change scenarios is unlikely to change regardless of which biogenic emissions were used.

For downscaling, both GEOS-Chem and CMAQ showed an increase of MDA8 ozone in the Midwest and Northeast domains due to climate change. However, disagreement of the ozone results was found in the Southeast domain, where the GEOS-Chem results showed insignificant changes, while CMAQ showed a small increase of MDA8 ozone. It is believed that the coarse resolution used in GEOS-Chem on the study was insufficient to represent the geospatial relationship in the complex terrain region. Moreover, the differences in chemical mechanism and lack of lightning emissions in CMAQ may also contribute the differences. For CMAQ $36 \mathrm{~km}$ and CMAQ $12 \mathrm{~km}$ study, no significant difference of output results (i.e., the difference between present and future conditions in domain-averaged MDA8 ozone and $\mathrm{PM}_{2.5}$ ) in the regional average was observed between those two resolutions. For the future climate condition, MDA8 ozone and average $\mathrm{PM}_{2.5}$ were strongly affected by both climate and emissions. Also, the emissions reduction had stronger effects on MDA8 ozone and average $\mathrm{PM}_{2.5}$ than the effects from climate change for all three domains. For ozone, the effect from climate change increased the MDA8 ozone by about $+2.0-2.5 \mathrm{ppbv}$, while the emissions reduction decreased the MDA8 ozone by about $+5.0-7.0$ ppbv. For $\mathrm{PM}_{2.5}, 90 \%$ of the reduction in the future concentration was contributed by the emission reduction, where the climate change was only contributed by about $10 \%$.

Acknowledgements. This work was supported by the US Environmental Protection Agency under STAR Agreement R833370 and the GCAP project. It has not formally been reviewed by the EPA. The views presented in this document are solely those of the authors and the EPA does not endorse any products or commercial services mentioned in this publication. We also thank NSF funded National Institute of Computational Sciences for us to use the Kraken supercomputer on this study. The partial of this work was also supported by the UT's Joint Directed Research and Development Program.

Edited by: T. Karl

\section{References}

Allen, D., Pickering, K., Pinder, R., Henderson, B., Koshak, W., and Pierce, T.: Impact of Lightning-NO Emissions on Eastern United States Photochemistry During the Summer of 2006 as Determined Using the CMAQ Model, The 9th Annual CMAS Conference, Chapel Hill, NC, USA, 11-13 October, 2010.

Arneth, A., Niinemets, Ü., Pressley, S., Bäck, J., Hari, P., Karl, T., Noe, S., Prentice, I. C., Serça, D., Hickler, T., Wolf, A., 
and Smith, B.: Process-based estimates of terrestrial ecosystem isoprene emissions: incorporating the effects of a direct $\mathrm{CO}_{2}$-isoprene interaction, Atmos. Chem. Phys., 7, 31-53, doi:10.5194/acp-7-31-2007, 2007.

Arunachalam, S., Holland, A., Do, B., and Abraczinskas, M.: A quantitative assessment of the influence of grid resolution on predictions of future-year air quality in North Carolina, USA, Atmos. Environ., 40, 5010-5026, 2006.

Avise, J., Chen, J., Lamb, B., Wiedinmyer, C., Guenther, A., Salathe, E., and Mass, C.: Attribution of projected changes in summertime US ozone and $\mathrm{PM}_{2.5}$ concentrations to global changes, Atmos. Chem. Phys., 9, 1111-1124, doi:10.5194/acp9-1111-2009, 2009.

Aw, J. and Kleeman, M. J.: Evaluating the first-order effect of intraannual temperature variability on urban air pollution, J. Geophys. Res., 108, 7-1, 2003.

Bell, M. L., Goldberg, R., Hogrefe, C., Kinney, P. L., Knowlton, K., Lynn, B., Rosenthal, J., Rosenzweig, C., and Patz, J. A.: Climate change, ambient ozone, and health in 50 US cities, Clim. Change, 82, 61-76, 2007.

Boylan, J. W.: Updates to CMAQ SOA Module and Kz_min Values, 3rd Particulate Matter/Regional Haze/Ozone Modeling Workshop, New Orleans, LA, USA, 19 May 2005.

Chin, M., Diehl, T., Ginoux, P., and Malm, W.: Intercontinental transport of pollution and dust aerosols: implications for regional air quality, Atmos. Chem. Phys., 7, 5501-5517, doi:10.5194/acp7-5501-2007, 2007.

Civerolo, K., Hogrefe, C., Lynn, B., Rosenthal, J., Ku, J.-Y., Solecki, W., Cox, J., Small, C., Rosenzweig, C., Goldberg, R., Knowlton, K., and Kinney, P.: Estimating the effects of increased urbanization on surface meteorology and ozone concentrations in the New York City metropolitan region, Atmos. Environ., 41, 1803-1818, 2007.

Dawson, J. P., Racherla, P. N., Lynn, B. H., Adams, P. J., and Pandis, S. N.: Simulating present-day and future air quality as climate changes: model evaluation, Atmos. Environ., 42, 45514566, 2008.

Duncan, B., Yoshida, Y., Retscher, C., Pickering, K., and Celarier, E.: The sensitivity of U.S. surface ozone formation to $\mathrm{NO}_{\mathrm{x}}$ and VOCs as viewed from space, The 8th Annual CMAS Conference, Chapel Hill, NC, USA, 19-21 October, 2009.

Fiore, A. M., Horowitz, L. M., Purves, D. W., Levy, H., II, Evans, M. J., Wang, Y., Li, Q., and Yantosca, R. M.: Evaluating the contribution of changes in isoprene emissions to surface ozone trends over the Eastern United States, J. Geophys. Res.-Atoms., 110(13), D12303, doi:10.1029/2004JD005485, 2005.

Gaza, R. S.: Mesoscale meteorology and high ozone in the Northeast United States, J. Appl. Meteorol., 37, 961-977, 1998.

Gilliam, R. C., Hogrefe, C., and Rao, S. T.: New methods for evaluating meteorological models used in air quality applications, Atmos. Environ., 40, 5073-5086, 2006.

Guenther, A. B., Zimmerman, P. R., Harley, P. C., Monson, R. K., and Fall, R.: Isoprene and monoterpene emission rate variability: model evaluations and sensitivity analyses, J. Geophys. Res., 98, 12609-12617, 1993.

Guenther, A. B., Karl, T., Harley, P., Wiedinmyer, C., Palmer, P. I., and Geron, C.: Estimates of global terrestrial isoprene emissions using MEGAN (Model of Emissions of Gases and Aerosols from Nature), Atmos. Chem. Phys., 6, 3181-3210, doi:10.5194/acp-6-
3181-2006, 2006.

Gustafson Jr., W. I. and Leung, L. R.: Regional downscaling for air quality assessment: a reasonable proposition?, B. Am. Meteorol. Soc., 88, 1215-1227, 2007.

Heald, C. L., Henze, D. K., Horowitz, L. W., Feddema, J., Lamarque, J. F., Guenther, A., Hess, P. G., Vitt, F., Seinfeld, J. H., Goldstein, A. H., and Fung, I.: Predicted change in global secondary organic aerosol concentrations in response to future climate, emissions, and land use change, J. Geophys. Res.-Atmos., 113, D05211, doi:10.1029/2007jd009092, 2008.

Hogrefe, C., Lynn, B., Civerolo, K., Ku, J. Y., Rosenthal, J., Rosenzweig, C., Goldberg, R., Gaffin, S., Knowlton, K., and Kinney, P. L.: Simulating changes in regional air pollution over the eastern United States due to changes in global and regional climate and emissions, J. Geophys. Res., 109, D22301, doi:10.1029/2004JD004690, 2004.

Hogrefe, C., Hao, W., Civerolo, K., Ku, J. Y., Sistla, G., Gaza, R. S., Sedefian, L., Schere, K., Gilliland, A., and Mathur, R.: Daily simulation of ozone and fine particulates over New York State: findings and challenges, J. Appl. Meteorol. Clim., 46, 961-979, 2007a.

Hogrefe, C., Lynn, B., Solecki, B., Cox, J., Small, C., Knowlton, K., Rosenthal, J., Goldberg, R., Rosenzweig, C., Civerolo, K., Ku, J. Y., Gaffin, S., and Kinney, P. L.: Air Quality in Future Decades - Determining the Relative Impacts of Changes in Climate, Emissions, Global Atmospheric Composition, and Regional Land Use, in: Air Pollution Modeling and Its Application XVII, 217-226, 2007b.

Huang, H. C. and Chang, J. S.: On the performance of numerical solvers for a chemistry submodel in three-dimensional air quality models 1. Box model simulations, J. Geophys. Res.-Atmos., 106, 20175-20188, 2001.

Huang, H.-C., Lin, J., Tao, Z., Choi, H., Patten, K., Kunkel, K., Xu, M., Zhu, J., Liang, X.-Z., Williams, A., Caughey, M., Wuebbles, D. J., and Wang, J.: Impacts of long-range transport of global pollutants and precursor gases on U.S. air quality under future climatic conditions, J. Geophys. Res.-Atoms., 113, D19307, doi:10.1029/2007JD009469, 2008.

Ito, A., Sillman, S., and Penner, J. E.: Global chemical transport model study of ozone response to changes in chemical kinetics and biogenic volatile organic compounds emissions due to increasing temperatures: sensitivities to isoprene nitrate chemistry and grid resolution, J. Geophys. Res.-Atoms., 114, D09301, doi:10.1029/2008JD011254, 2009.

Jacob, D. J. and Winner, D. A.: Effect of climate change on air quality, Atmos. Environ., 43, 51-63, 2009.

Jacobson, M. Z. and Streets, D. G.: Influence of future anthropogenic emissions on climate, natural emissions, and air quality, J. Geophys. Res.-Atoms., 114, D08118, doi:10.1029/2008JD011476, 2009.

Jiang, X., Wiedinmyer, C., Chen, F., Yang, Z.-L., and Lo, J. C. F.: Predicted impacts of climate and land use change on surface ozone in the Houston, Texas, area, J. Geophys. Res.-Atoms., 113, D20312, doi:10.1029/2008JD009820, 2008.

Jiang, X. Y., Yang, Z. L., Liao, H., and Wiedinmyer, C.: Sensitivity of biogenic secondary organic aerosols to future climate change at regional scales An online coupled simulation, Atmospheric Environment, 44, 4891-4907, DOI 10.1016/j.atmosenv.2010.08.032, 2010. 
Kim, Y., Fu, J. S., and Miller, T. L.: Improving ozone modeling in complex terrain at a fine grid resolution: Part I - examination of analysis nudging and all PBL schemes associated with LSMs in meteorological model, Atmos. Environ., 44, 523-532, 2010.

Kleinman, L. I., Daum, P. H., Imre, D. G., Lee, J. H., Lee, Y.N., Nunnermacker, L. J., Springston, S. R., Weinstein-Lloyd, J., and Newman, L.: Ozone production in the New York City urban plume, J. Geophys. Res.-Atoms., 105, 14495-14511, 2000.

Knutti, R., Allen, M. R., Friedlingstein, P., Gregory, J. M., Hegerl, G. C., Meehl, G. A., Meinshausen, M., Murphy, J. M., Plattner, G. K., Raper, S. C. B., Stocker, T. F., Stott, P. A., Teng, H., and Wigley, T. M. L.: A review of uncertainties in global temperature projections over the twenty-first century, J. Climate, 21, 26512663, 2008.

Kunkel, K., Huang, H. C., Liang, X. Z., Lin, J. T., Wuebbles, D., Tao, Z., Williams, A., Caughey, M., Zhu, J., and Hayhoe, K.: Sensitivity of future ozone concentrations in the northeast USA to regional climate change, Mitigat. Adapt. Strateg. Glob. Change, 13, 597-606, 2008.

Lam, Y. F., and Fu, J. S.: Corrigendum to "A novel downscaling technique for the linkage of global and regional air quality modeling” published in Atmos. Chem. Phys., 9, 9169-9185, 2009, Atmos. Chem. Phys., 10, 4013-4031, doi:10.5194/acp-10-40132010, 2010.

Mickley, L. J., Jacob, D. J., Rind, D., and Streets, D.: Effects of 2000-2050 global change on U.S. ozone air quality, AGU Fall meeting, San Francisco, CA, 11-15 December, 2006.

Milford, J. B., Russell, A. G., and McRae, G. J.: A new approach to photochemical pollution control: Implications of spatial patterns in pollutant responses to reductions in nitrogen oxides and reactive organic gas emissions, Environ. Sci. Technol., 23, 12901301, 1989.

Milford, J. B., Gao, D., Sillman, S., Blossey, P., and Russell, A. G.: Total reactive nitrogen (NOy) as an indicator of the sensitivity of ozone to reductions in hydrocarbon and NOx emissions, J. Geophys. Res., 99, 3533-3542, 1994.

Nolte, C. G., Gilliland, A. B., Hogrefe, C., and Mickley, L. J.: Linking global to regional models to assess future climate impacts on surface ozone levels in the United States, J. Geophys. Res.Atoms., 114, D14307, doi:10.1029/2007JD008497, 2008.

Park, R. J., Jacob, D. J., Fairlie, D. T., Alexander, B., and Yantosca, R. M.: Natural and transboundary pollution influences on aerosol concentrations and visibility degradation in the United States, in: Regional and Global Perspectives on Haze, Asheville, NC, USA, 963-967, 2004.

Pouliot, G.: A Tale of Two Models: A Comparison of the Biogenic Emission Inventory System (BEIS3.14) and Model of Emissions of Gases and Aerosols from Nature (MEGAN 2.04), 7th Annual CMAS Conference, Chapel Hill, NC, USA, 7 October 2008.

Pouliot, G. and Pierce, T. E.: Integration of the Model of Emissions of Gases and Aerosols from Nature (MEGAN) into the CMAQ Modeling System, 18th International Emission Inventory Conference, Baltimore, Maryland, 14-17 April 2009.

Queen, A., Zhang, Y., Gilliam, R., and Pleim, J.: Examining the sensitivity of MM5-CMAQ predictions to explicit microphysics schemes and horizontal grid resolutions, Part I-database, evaluation protocol, and precipitation predictions, Atmos. Environ., 42, 3842-3855, 2008.

Racherla, P. N. and Adams, P. J.: The response of surface ozone to climate change over the Eastern United States, Atmos. Chem. Phys., 8, 871-885, doi:10.5194/acp-8-871-2008, 2008.

Rind, D., Lean, J., and Healy, R.: Simulated time-dependent climate response to solar radiative forcing since 1600 , J. Geophys. Res. 104, 1973-1990, 1999.

Rind, D., Lerner, J., Jonas, J., and McLinden, C.: Effects of resolution and model physics on tracer transports in the NASA Goddard Institute for Space Studies general circulation models, J. Geophys. Res., 112, D09315, doi:10.1029/2006JD007476, 2007.

Sakamoto, K., Takada, H., and Sekiguchi, K.: Influence of ozone, relative humidity, and flow rate on the deposition and oxidation of sulfur dioxide on yellow sand, Atmos. Environ., 38, 69616967, 2004.

Sakulyanontvittaya, T., Duhl, T., Wiedinmyer, C., Helmig, D., Matsunaga, S., Potosnak, M., Milford, J., and Guenther, A.: Monoterpene and sesquiterpene emission estimates for the United States, Environ. Sci. Technol., 42, 1623-1629, 2008.

Schmidt, G. A., Ruedy, R., Hansen, J. E., Aleinov, I., Bell, N., Bauer, M., Bauer, S., Cairns, B., Canuto, V., Ye, C., Del Genio, A., Faluvegi, G., Friend, A. D., Hall, T. M., Yongyun, H., Kelley, M., Kiang, N. Y., Koch, D., Lacis, A. A., Lerner, J., Lo, K. K., Miller, R. L., Nazarenko, L., Oinas, V., Perlwitz, J., Rind, D., Romanou, A., Russell, G. L., Sato, M., Shindell, D. T., Stone, P. H., Sun, S., Tausnev, N., Thresher, D., and Mao-Sung, Y.: Present-day atmospheric simulations using GISS ModelE: comparison to in situ, satellite, and reanalysis data, J. Climate, 19, 153-192, 2006.

Streets, D. G., Bond, T. C., Lee, T., and Jang, C.: On the future of carbonaceous aerosol emissions, J. Geophys. Res., 109, D24212, doi:10.1029/2004JD004902, 2004.

Tagaris, E., Manomaiphiboon, K., Liao, K.-J., Leung, L. R., Woo, J.-H., He, S., Amar, P., and Russell, A. G.: Impacts of global climate change and emissions on regional ozone and fine particulate matter concentrations over the United States, J. Geophys. Res.-Atoms., 112, D14312, doi:10.1029/2006JD008262, 2007.

Tai, A. P. K., Mickley, L. J., and Jacob, D. J.: Correlations between fine particulate matter $\left(\mathrm{PM}_{2.5}\right)$ and meteorological variables in the United States: Implications for the sensitivity of $\mathrm{PM}_{2.5}$ to climate change, Atmos. Environ., 44, 3976-3984, 2010.

Vingarzan, R.: A review of surface ozone background levels and trends, Atmos. Environ., 38, 3431-3442, 2004.

Weaver, C. P., Liang, X. Z., Zhu, J., Adams, P. J., Amar, P., Avise, J., Caughey, M., Chen, J., Cohen, R. C., Cooter, E., Dawson, J. P., Gilliam, R., Gilliland, A., Goldstein, A. H., Grambsch, A., Grano, D., Guenther, A., Gustafson, W. I., Harley, R. A., He, S., Hemming, B., Hogrefe, C., Huang, H. C., Hunt, S. W., Jacob, D. J., Kinney, P. L., Kunkel, K., Lamarque, J. F., Lamb, B., Larkin, N. K., Leung, L. R., Liao, K. J., Lin, J. T., Lynn, B. H., Manomaiphiboon, K., Mass, C., McKenzie, D., Mickley, L. J., O’Neill, S. M., Nolte, C., Pandis, S. N., Racherla, P. N., Rosenzweig, C., Russell, A. G., Salathe, E., Steiner, A. L., Tagaris, E., Tao, Z., Tonse, S., Wiedinmyer, C., Williams, A., Winner, D. A., Woo, J. H., Wu, S., and Wuebbles, D. J.: A preliminary synthesis of modeled climate change impacts on U.S. regional ozone concentrations, B. Am. Meteorol. Soc., 90, 1843-1863, 2009.

Wu, S., Mickley, L. J., Jacob, D. J., Logan, J. A., Yantosca, R. M., and Rind, D.: Why are there large differences between models in global budgets of tropospheric ozone?, J. Geophys. Res.-Atoms., 112, D05302, doi:10.1029/2006JD007801, 2007. 
Wu, S., Mickley, L. J., Jacob, D. J., Rind, D., and Streets, D. G.: Effects of 2000-2050 changes in climate and emissions on global tropospheric ozone and the policy-relevant background surface ozone in the United States, J. Geophys. Res.-Atoms., 113, D18312, doi:10.1029/2006JD007801, 2008a.

Wu, S., Mickley, L. J., Leibensperger, E. M., Jacob, D. J., Rind, D., and Streets, D. G.: Effects of 2000-2050 global change on ozone air quality in the United States, J. Geophys. Res.-Atoms., 113, doi:10.1029/2007JD008917, 2008b.
Zhang, Y., Hu, X.-M., Leung, L. R., and Gustafson Jr., W. I.: Impacts of regional climate change on biogenic emissions and air quality, J. Geophys. Res.-Atoms., 113, D18310, doi:10.1029/2008JD009965, 2008. 